Proc. Indian Acad. Sci. (Earth Planet. Sci.), Vol. 103, No. 1, March 1994, pp. 57-82.

(C) Printed in India.

\title{
Isotopic analysis of early solar system objects by an ion microprobe: Parametric studies and initial results
}

\author{
J N GOSWAMI and G SRINIVASAN \\ Physical Research Laboratory, Navrangpura, Ahmedabad 380009, India \\ MS received 7 December 1993; revised 15 April 1994
}

\begin{abstract}
Magnesium, potassium and calcium isotope compositions in terrestrial samples and refractory phases from primitive meteorites are determined using an ion microprobe. A thorough investigation of the different instrument parameters is carried out to ensure that conditions necessary for high mass resolution and high precision isotopic studies are adequately satisfied. The instrument can be tuned to achieve mass resolution $(M / \Delta M)$ of up to $10,000(M \leqslant 60)$, it has a very good dynamic stability $(\Delta B / B \leqslant 10 \mathrm{ppm}$ over durations of $\leqslant 40$ minutes) and the counting system has an effective dead-time of $\leqslant 25 \mathrm{nsec}$ and a dynamic background of $\leqslant 0.01 \mathrm{c} / \mathrm{s}$. Reproducibility and precision of isotopic measurements are checked by analyzing magnesium and titanium isotopic compositions in terrestrial standards and isotopically doped silicate glasses. A precision of $2 \%\left(2 \sigma_{m}\right)$ was achieved during magnesium isotopic analysis in samples with low $\mathrm{Mg}$ content $(200 \mathrm{ppm})$. Results from studies of magnesium and potassium isotopic compositions in several $\mathrm{Ca}$-Al-rich refractory inclusions (CAIs) from the primitive meteorites Efremovka and Grosnaja, representing some of the early solar system objects, are presented. The well-behaved $\mathbf{M g}$-Al isotopic systematics confirm the pristine nature of the Efremovka CAIs inferred earlier from petrographic and trace element studies. The Grosnaja CAIs that have experienced secondary alterations show disturbed magnesium isotopic systematics. Observation of excess ${ }^{26} \mathrm{Mg}$ in several of the analyzed CAIs confirms the presence of the now extinct ${ }^{26} \mathrm{Al}\left(t_{1 / 2}=7 \times 10^{5}\right.$ years $)$ in the solar nebula at the time of CAI formation. Our data also suggest a relatively uniform distribution of ${ }^{26} \mathrm{Al}$ in the solar nebula. Several Efremovka CAIs with excess ${ }^{26} \mathrm{Mg}$ also have excess ${ }^{41} \mathrm{~K}$ resulting from the decay of ${ }^{41} \mathrm{Ca}\left(t_{1 / 2} \simeq 10^{5}\right.$ years). This observation constrains the time interval between cessation of nucleosynthetic input to the solar nebula and the formation of some of the first solar system solids (CAIs) to less than a million years.
\end{abstract}

Keywords. Ion microprobe; isotopes; extinct nuclides; meteorites; solar system; solar nebula.

\section{Introduction}

Refractory mineral phases [e.g. corundum $\left(\mathrm{Al}_{2} \mathrm{O}_{3}\right)$, hibonite $\left(\mathrm{CaAl}_{12} \mathrm{O}_{19}\right)$, perovskite $\left(\mathrm{CaTiO}_{3}\right)$, spinel $\left(\mathrm{MgAl}_{2} \mathrm{O}_{4}\right)$, fassaite ( $\mathrm{Ti}$, Al-rich pyroxene), melilite, anorthite, diopside] and their assemblages that occur in certain primitive meteorites and collectively termed as $\mathrm{Ca}-\mathrm{Al}$-rich refractory inclusions (CAls) are considered to be some of the first solids to have formed in the solar system. Their mineralogical make-up and chemical composition are consistent with what one would expect for the first solid phases to condense during the cooling of an initially hot solar nebula - the gas and dust cloud from which the solar system is believed to have evolved (Grossman 1972, 1980; Macdougall and Goswami 1981). A variety of studies on CAIs including petrography, major element chemistry, trace element abundances and isotopic compositions have been carried out to understand the processes leading 
to their formation and what they tell us about the early evolutionary epoch of the solar system (for a comprehensive review see MacPherson et al 1988). The isotopic studies, in particular, have led to several important results that have changed many of the earlier ideas about the formation and early evolution of the solar system. It was shown that the solar nebula was not isotopically homogeneous (Clayton et al 1973 ) and short-lived now-extinct nuclei (e.g. ${ }^{26} \mathrm{Al}$ :half life $=7 \times 10^{5} \mathrm{yr}$ ) were present in the solar nebula and incorporated 'live' into some of the CAIs (Lee et al 1976). Evidence for the presence of distinct stellar nucleosynthetic products that were most probably transported from their source sites to the solar nebula by interstellar dust was also found. The gradual progress made in the field of isotopic studies of early solar system objects has been discussed in a series of review articles (Clayton 1978; Podosek 1978; Lee 1979, 1988; Begemann 1980; Wasserburg et al 1980; Wasserburg and Papanastassiou 1982; Wasserburg 1985; Clayton et al 1988; Thiemens 1988; Harper 1993).

The isotopic studies of the $\mathrm{Ca}$-Al-rich refractory inclusions (CAIs) were initially carried out using conventional thermal ionization mass spectrometric (TIMS) techniques. While these studies generated several new and exciting results, they also raised many new questions, and it was soon realized that resolving these questions would require further in-depth studies of isotopic compositions in individual phases comprising the CAIs. The small sizes of the individual phases, generally less than hundred microns, made such analysis an extremely difficult proposition. Although some attempts were made to use the TIMS technique to analyze separated mineral phases of individual CAIs (e.g. Niederer and Papanastassiou 1984; Jungck et al 1984), the need for in situ analysis of micro-phases in the refractory inclusions remained. The breakthrough came with the successful application of the high mass resolution secondary ion mass spectrometer (SIMS) or the ion microprobe for such studies during the last decade (Hutcheon 1982; Huneke et al 1983; Fahey et al 1985, 1987; Ireland et al 1985). Successful application of the ion microprobe for isotopic studies of meteoritic micro-phases depends on the capability of the instrument to resolve isobaric interferences and its dynamical stability during isotopic measurements at high mass resolution. The mass resolving power (MRP:M/ $\Delta M$ ) needed to resolve isobaric interferences is rather high, exceeding a few thousand in general and often close to 10,000 . Since the commercially available ion microprobes could barely reach the high MRP needed, it is extremely important to carry out detailed parametric investigations to establish the capability of an individual instrument for precise isotopic analysis. In this paper, we describe the basic working principle of a commercially available ion microprobe (Cameca IMS-4f) acquired by us and present results obtained from parametric studies that establish the suitability of the instrument for high precision measurements of isotopic compositions of terrestrial and meteoritic samples. The studies carried out include proper tuning of the instrument to resolve isobaric interferences that require MRP $\leqslant 10,000$, dynamic stability of the instrument during isotopic measurements at high mass resolution, and precision and reproducibility that can be achieved during measurement of isotopic compositions of terrestrial standards and isotopically doped samples. We then present the results obtained from our initial studies of isotopic compositions of magnesium, calcium and potassium in a set of $\mathrm{Ca}-\mathrm{Al}$-rich refractory inclusions (CAIs) from the primitive carbonaceous chondrites, Efremovka and Grosnaja. 


\section{Instrument and experimental procedures}

The high mass resolution Cameca IMS-4f ion microprobe is a double focusing mass spectrometer with the unique capability of ion imaging as well. A schematic of the ion microprobe is shown in figure 1 with ideal traces of the ion optics. The instrument has two primary ion sources, a duoplasmatron that can generate positive or negative ion beams of a variety of atomic and molecular species, and a thermal ionization source used for generating a $\mathrm{Cs}^{+}$ion beam. The primary ions are extracted by floating the source at high potential (variable from 5 to $15 \mathrm{kV}$ ) and using a grounded extraction lens. The extracted beam passes through a mass filter with variable resolving power $(M / \Delta M \leqslant 100)$ that removes spurious ions. The beam then passes through a series of focussing electrostatic lenses, apertures, deflectors and stigmators that allow one to focus the primary beam on to the sample surface. The size of the focussed beam spot can be as small as a few microns, and is a function of the beam current which can be varied from a few picoamperes to a few hundred nanoamperes.

The primary ion beam sputters atomic and molecular species, both neutral and ionized, from the sample surface. The ionized atomic and molecular species, called the secondary ions, are accelerated through a grounded electrode with a circular hole. This electrode is placed a few mm away from the sample surface, held at $\pm 4.5 \mathrm{kV}$, the polarity depending upon whether positive or negative secondary ions are chosen for analysis. The energetic secondary ion beam is then directed towards the entrance slit of the mass spectrometer using a lens system, termed the transfer optics, in which the grounded extraction lens acts as the first element. Since the field near the extraction hole is not uniform, but has strong radial components, it acts like a divergent lens producing both a virtual image of the sample surface and a virtual cross-over that reflects the lateral energy distribution of the secondary ions. The function of this lens system is to transfer the virtual images formed by the extraction lens into real and magnified images of the cross-over and the sample surface at the plane of the contrast and field apertures respectively. One can select different combinations of lenses in the transfer optics system to obtain imaged fields of 25,150 and $250 \mu \mathrm{m}$. The contrast aperture, placed nearly coincident with the entrance slit of the mass spectrometer is located on the focal plane of the cross-over and the field aperture is placed near the focal plane of the electrostatic analyzer and is also coincident with the real image of the sample surface.

The secondary ions sputtered from the sample surface have an energy spread of $\sim 100 \mathrm{eV}$. In order to avoid chromatic aberration that can result from such an energy spread a double focussing system is used. It consists of a combination of an electrostatic analyzer (ESA) which disperses ions as a function of their energy and a magnetic sector which disperses them as a function of mass. Ions with the same mass but different energies are dispersed in energy by the ESA and are brought to focus by the magnetic sector. The ESA consists of two concentric electrodes that are held at fixed potentials so that ions with nominal energy of $4.5 \mathrm{keV}$ follow the central beam path and other ions are dispersed in energy along the radial direction of the electrostatic analyzer. This offers the possibility to choose secondary ions within a narrow energy band by using the energy slit placed after the ESA. The energy-selected beam then passes through the magnet which disperses ions according to their mass to charge $(\mathrm{m} / \mathrm{q})$ ratio. The mass analyzed ions are received by the detector through 


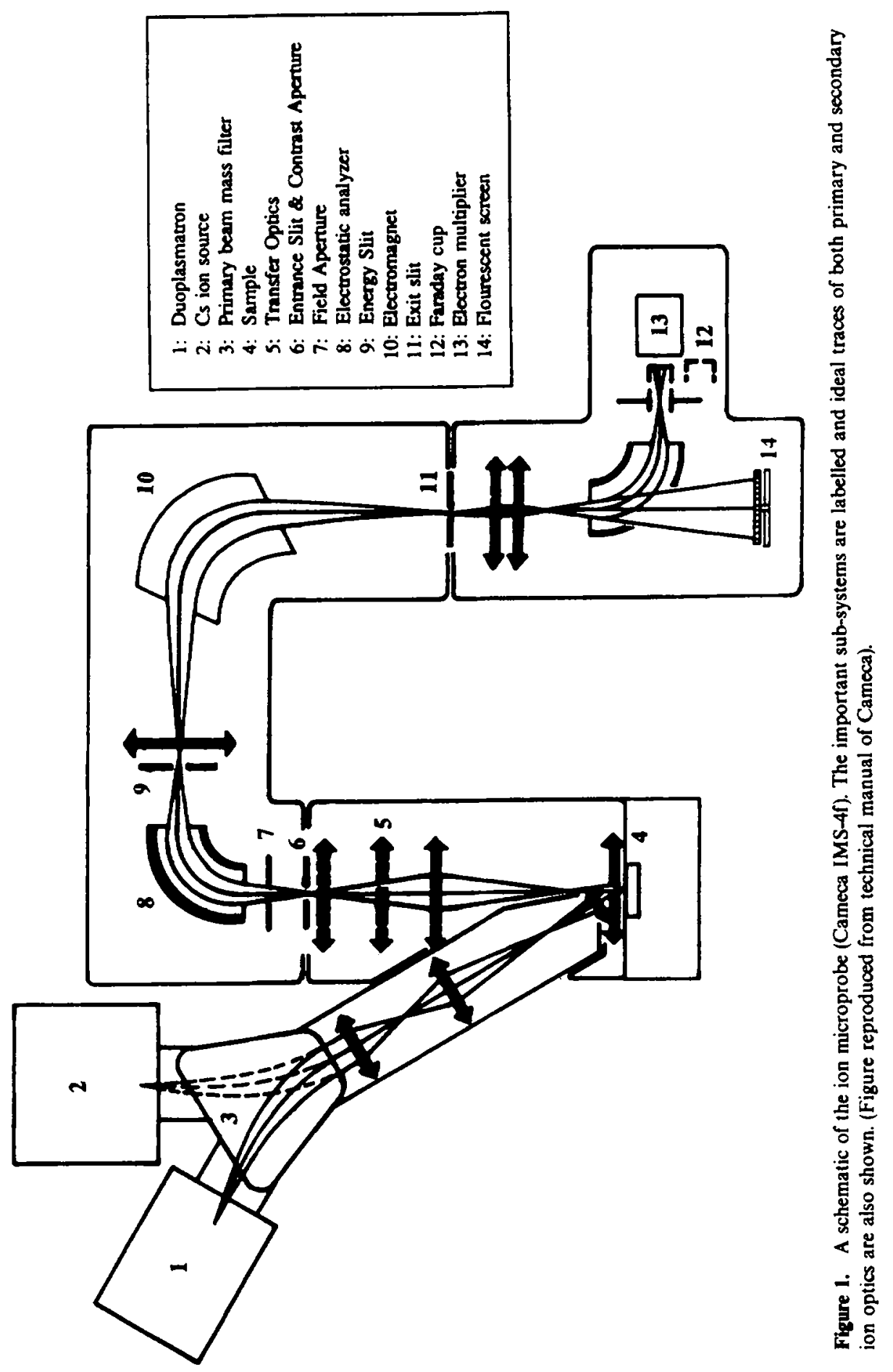


an exit slit and a set of deflector, stigmator and projector lenses. The entrance and exit slits are adjusted to achieve the desired mass resolution. One has several options at the detector end: a channel plate coupled to a fluorescent screen can be used to obtain an ion-image, or, one can measure the ion-intensity by using conventional faraday cup or pulse-counting system. A detailed description of the ion optics of the Cameca ion microprobe is given by Lepareur (1980).

A focussed primary ion beam with a current in the nanoampere range is generally used for isotopic analysis. The choice of the primary beam depends on the element(s) of interest. The electronegative elements (e.g. $\mathrm{H}, \mathrm{C}, \mathrm{O}, \mathrm{S}$ etc.) give a higher yield of negative ions during sputtering, and one generally uses a positive primary ion beam (e.g. $\mathrm{Cs}^{+}$) to analyze such negative secondary ions. On the other hand, a combination of a negative primary ion beam $\left({ }^{16} \mathrm{O}^{-}\right)$and positive secondary ions is generally used for isotopic analysis of elements like $\mathrm{Mg}, \mathrm{K}, \mathrm{Ca}, \mathrm{Ti}, \mathrm{Fe}$ etc. In the present work, we have used a $17 \mathrm{keV}$ focused ${ }^{16} \mathrm{O}^{-}$ion beam for determining the isotopic compositions of $\mathrm{Mg}, \mathrm{Ca}, \mathrm{K}$ and $\mathrm{Ti}$ in meteoritic minerals and their terrestrial analog phases. $\mathrm{A}$ $14.5 \mathrm{keV} \mathrm{Cs}^{+}$primary ion beam was used for oxygen isotopic analysis. Studies of negative secondaries from insulating solids like the common terrestrial and meteoritic minerals have the added problem of sample charging. This results from the use of a positive primary ion beam to sputter the sample surface held at a constant and high negative potential $(-4.5 \mathrm{kV})$. The sample charging problem was avoided by using an electron gun to generate an extremely low energy electron cloud near the sample surface to neutralize the excess positive charge (Slodzian et al 1987).

The samples to be analyzed are potted in epoxy, polished and coated with gold $(\sim 1000 \AA)$ prior to ion microprobe analysis. A $150 \mu \mathrm{m}$ imaged field is chosen, and the combination of a $150 \mu \mathrm{m}$ contrast aperture and a $750 \mu \mathrm{m}$ field aperture is generally used for normal operation. For certain analyses (e.g. isotopic studies of oxygen and potassium) we have used smaller field apertures $(200 \mu \mathrm{m})$ to restrict the field of view from which secondary ions are accepted for analysis. The width of the entrance and exit slits are appropriately adjusted for the desired mass resolution and the alignment of the slits is done carefully to have a flat-top peak with sharp shoulders at any given mass (see figure 2). The ion-imaging mode of the instrument allows this adjustment to be done with ease as one can image the entrance slit and move it across the exit slit by scanning the magnetic field across the mass of interest. The most appropriate ESA voltages for analysis in both positive and negative secondary ion modes are determined initially and are kept fixed at these preset values during analysis. Any fine tuning, if needed. is done by moving the ion beam with the help of deflectors in the transfer optics system placed before the contrast aperture. An energy window of 25 volts is generally chosen during analysis and the energy distribution of the secondary ions is monitored before and after each analysis to ensure that there is no drift in the energy band of the secondary ions selected for mass analysis. The isotopic measurements are done in the peak jumping mode by cycling the magnet through the masses of interest and repeating this for a sufficient number of times to get enough counting statistics at each of the masses of interest. Prior to actual measurement, the magnetic field values for each of the analyzed masses are set to correspond to the centers of each of the mass peaks. The magnet is then cycled through these calibrated field values, and recalibration and cycling of the magnet is repeated until there is no appreciable drift in the calibrated field values corresponding to the different masses. Recalibration of the magnetic field is also done at suitable intervals during actual 


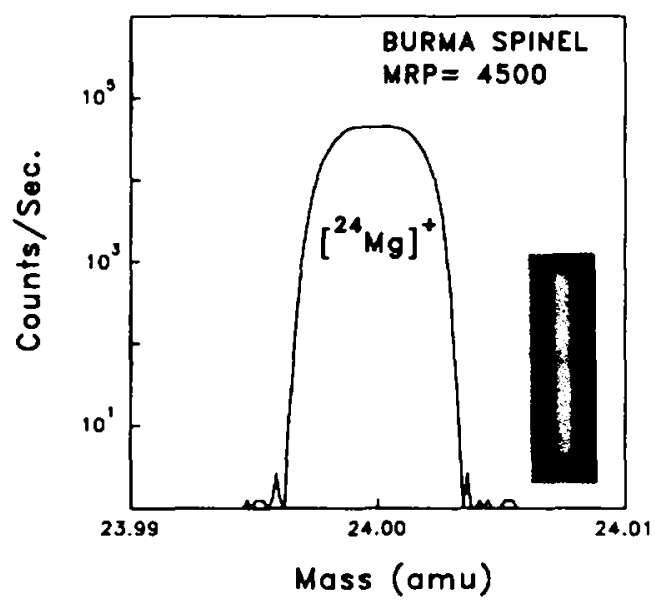

Figure 2. High mass resolution spectra at mass 24 (magnesium) obtained in a terrestrial spinel showing well-defined peak shape with a flat top and smooth and sharply falling peak shoulders. The inset shows the ${ }^{24} \mathrm{Mg}$ ion-image of the sharply defined entrance slit.

analysis. All the measurements are done using the pulse counting system which is checked periodically for its stability and efficiency. In the next section we discuss the results of parametric studies that were carried out to ensure the feasibility of high mass resolution and high precision isotopic analysis by our ion microprobe.

\section{Parametric studies and results}

The important requirements for isotopic analysis by an ion microprobe are: (i) resolution of isobaric interferences at the mass(es) of interest and (ii) dynamic stability during high mass resolution measurement. In addition, a proper ion-counting system is extremely important for high precision analysis. In this section, we discuss these three stringent requirements and demonstrate that they have been met by our ion microprobe.

\subsection{Isobaric interferences}

The sputtering of the sample surface by the primary ion beam leads to the generation of a variety of secondary ions that include single or multiple-charged atomic species as well as molecular ions (primarily hydrides, oxides, and other dimers and trimers) depending upon the composition of the sample matrix. Any of these secondary ions with mass to charge ratio close but not equal to that of the ion(s) of interest will act as interfering species. Resolving such interferences e.g. $(\mathbf{M} \pm \dot{\Delta} \mathbf{M}),[(\mathbf{M}-1) \mathbf{H}]$, [(M-16)O] etc. $\}$ at mass $M$ demands specific mass resolving power. The hydride interferences in the low mass region $(A<60)$ are generally separated from the main mass by $\sim 0.008 \mathrm{amu}$. They can therefore be resolved with a mass resolving power $(M / \Delta M)$ of several thousands (where $\Delta M$ is the width of the peak at $10 \%$ of the maximum count rate at mass $M$ ). Separation of true isobaric interferences often 

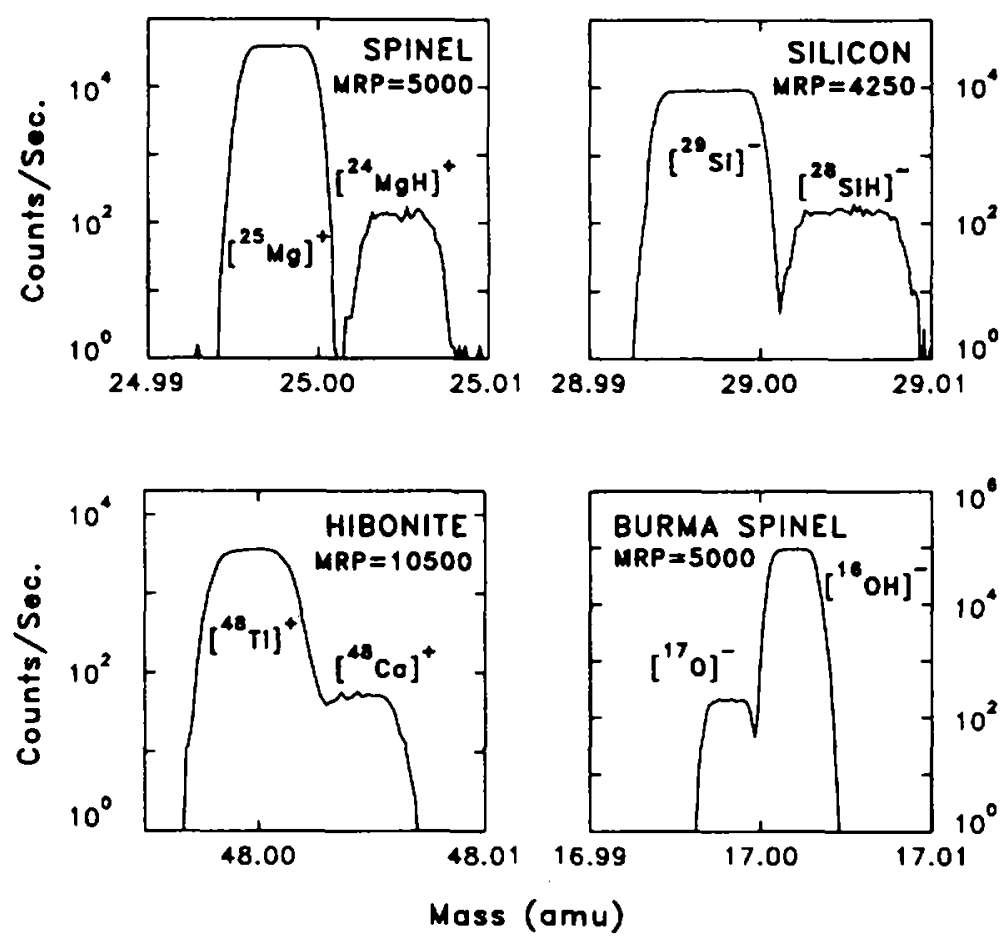

Figure 3. High mass resolution spectra at masses 25 (magnesium), 48 (calcium and titanium), 29 (silicon) and 17 (oxygen) showing well resolved hydride and true isobaric interferences. The mass resolving power and the sample analyzed in each case are also indicated.

demands much higher mass resolution $(\sim 10,000)$ as the mass difference between the isobars are generally much smaller (e.g. $00046 \mathrm{amu}$ in the case of ${ }^{48} \mathrm{Ca}$ and ${ }^{48} \mathrm{Ti}$ ). Isobaric pairs that are separated in mass by even smaller values (e.g. 0.001 amu for ${ }^{46} \mathrm{Ti}$ and ${ }^{46} \mathrm{Ca} ; 0.0013 \mathrm{amu}$ for ${ }^{50} \mathrm{Ti}$ and ${ }^{50} \mathrm{Cr}$ ) and hydride interferences in the high mass $(A>100)$ region cannot be resolved adequately by an ion microprobe. In such cases one has to resort to indirect means of correction (e.g. peak stripping, energy filtering techniques etc.). Such corrections, however, are not unique in all the cases. Because of these difficulties ion microprobe studies of isotopic compositions of terrestrial and meteorite samples are at present restricted primarily to the low mass $(\mathrm{A}<70)$ and the very heavy mass $(\mathrm{U}-\mathrm{Pb})$ regions.

We have been able to tune the ion microprobe routinely for resolving hydride interferences in the low mass region. Tuning of the instrument for higher mass resolution, as needed in certain cases (e.g. analysis of $\mathrm{Ti}$ and $\mathrm{Ca}$ isotopic compositions in a sample containing both elements), could also be achieved with some additional effort. Special care is taken to ensure that the primary ion beam is well focussed and stable and there is no sample charging effect during the tuning of the secondary ions. The typical stability of the primary beam is found to be better than a few per mil in the nanoampere range. In figure 3 we show high mass resolution spectra at masses 17 (oxygen), 25 (magnesium), 29 (silicon) and 48 (titanium and calcium) that clearly demonstrate good separation of hydride and pure isobaric interferences. The spectrum 
for oxygen at mass 17 was obtained in a terrestrial spinel using the $\mathrm{Cs}^{+}$primary ion beam and in the negative secondary mode. The normal incidence electron gun was also used to avoid the problem of sample charging. The other mass spectra were obtained in the positive secondary mode using a negative $\left({ }^{16} \mathrm{O}^{-}\right)$primary ion beam.

\subsection{Dynamic stability}

Isotopic analysis by the ion microprobe is done in the flat-top peak jumping mode. In this mode of analysis, the magnetic field values for the peak centers of the masses of interest are provided and the magnet is cycled through these values with suitable counting time at each mass. The Cameca-Ims $4 f$ ion microprobe has an 18 bit magnetic field control ( $\sim 2.6 \times 10^{5}$ field bits) for generating field values within any one of the three preselected mass ranges $(0-20,0-80,0-280)$. At high mass-resolution, the flat-top peaks (see figure 3 ) represent a very small mass (magnetic field) interval (nominally $\sim 0.003 \mathrm{amu} ; 10-15$ field bits) while operating in the 0-80 mass range. Any minor instability in the instrument during peak jumping and cycling can, in principle, move the preset field value for an analyzed mass out of the flat-top region leading to erroneous count rates. It is therefore essential that the instrument has a very good dynamic stability during isotopic measurements. An 'effective' stability of the magnetic field with $\Delta \mathrm{B} / \mathrm{B} \sim 10 \mathrm{ppm}$ (equivalent to $\Delta \mathrm{M} / \mathrm{M} \sim 20 \mathrm{ppm}$ ) is necessary in this context. We have taken several precautions to ensure a high degree of dynamic stability of the instrument. These include an extremely stable power supply for the electrostatic analyzer $(\Delta V / V<10 \mathrm{ppm})$, temperature fluctuation less than $\pm 1^{\circ} \mathrm{C}$ in both the ESA and magnet environment and the use of preadjusted ESA settings during tuning and analysis. In figure 4 , we show the results obtained by us that allow an estimation of the level of dynamic stability of the system during high mass resolution $(\mathrm{M} / \Delta \mathrm{M}$ $\sim 5,000$ ) analysis in the peak jumping mode. Two mass-regions $24-26$ and $46-50$ were investigated. We have obtained count rates at the peak centers of the chosen masses and also at a position in the rising left shoulder of each peak where the count rate is less than half of that at the peak center. Since the count rate on the peak shoulder is very sensitive to small changes in the magnetic field, its variation during the analysis provides an estimate of the magnitude of the mass shift $\Delta M$, relative to the main mass $M$. This can then be expressed in terms of $(\Delta B / B)$ which provides a measure of the 'effective' dynamic stability of the instrument. As noted in the figure the value of $\Delta \mathrm{M} / \mathrm{M}$ for both the mass ranges is $\sim 2 \times 10^{-3}$ which is equivalent to a stability in $\triangle B / B$ of $\sim 10 \mathrm{ppm}$. Even though the dynamic stability of the instrument is extremely good over long periods (30-40 minutes; see figure 4 ), we prefer to recalibrate the magnet at intervals of $\sim 5$ minutes during isotopic measurements to guard against possible short-term drift. We find that the shift in the field values for the peak center during such recalibration is not more than one or two field bits. Since the width of the flat top typically represents 10 to 15 field bits, the dynamic stability of the instrument is sufficient for high mass resolution isotopic analysis in the peak jumping mode.

The stability of the pulse counting system and a low background are extremely important for high precision isotopic measurement. We monitor the background, efficiency and dead-time of the pulse counting system periodically to ensure that any change in these parameters are properly taken into account during analysis. The checks are done for the total counting system (pre-amplifier, discriminator, electron 

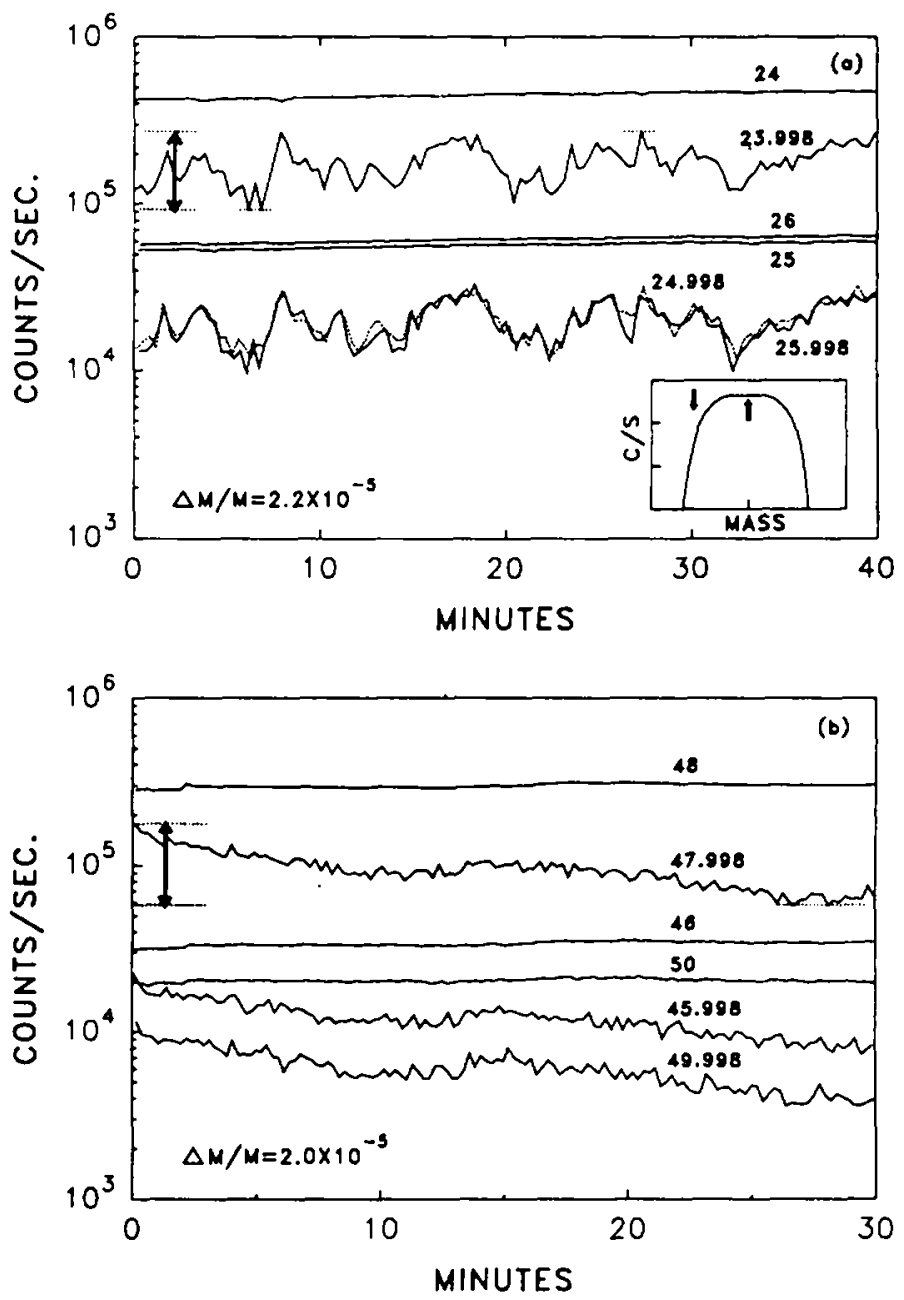

Figure 4a \& b. Count rates at the peak center (integer masses) and to the left of the peak center (non-integer masses) plotted as a function of time (see inset for approximate positions at which the count rates were monitored). Two mass ranges: 24-26 (figure 4a) and 46-50 (figure 4b) are investigated in the dynamic (peak-jumping) mode of analysis. The value of $\Delta M / M$ obtained from the maximum variation in the count-rate at the peak shoulders (marked in both figures) is also shown in each case.

multiplier and the counting electronics) in an operative way by analyzing standard samples. For example, the system dead-time is estimated from measurements of magnesium and titanium isotopic compositions in terrestrial spinel and in Ti-metal respectively. The isotopic measurements are made at a mass resolution sufficient to rer.ove the hydride interferences and the deviations in the measured isotopic ratios from reference values are attributed to the combined effect of mass fractionation and dead-time of the counting system. Since the magnitude of isotopic mass fractionation can be estimated by using an appropriate mass fractionation law, the effective dead-time of the counting system can be determined. The results obtained from a series of magnesium isotopic analyses of terrestrial spinel during ear'y 1993 are shown 


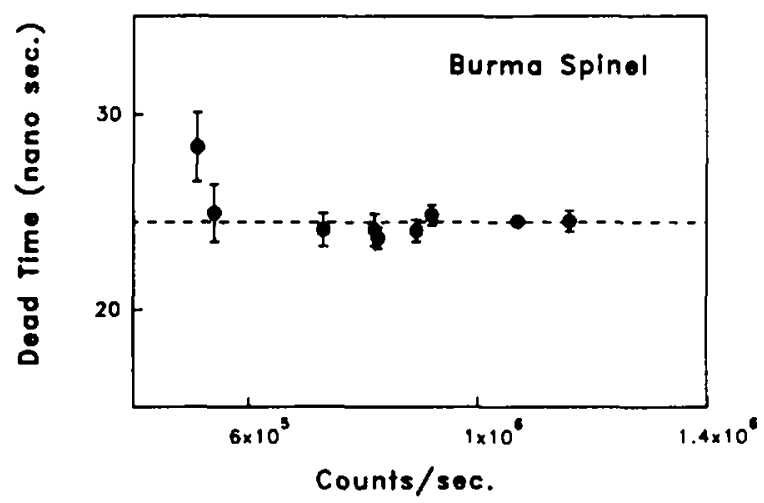

Figure 5. Dead-time of the integrated pulse counting system as a function of count-rate obtained from magnesium isotopic measurements in terrestrial spinel. Error bars are $2 \sigma_{m}$.

in figure 5. The effective dead-time of the counting system remained nearly the same (24 \pm 1 nanosec) for ${ }^{24} \mathrm{Mg}$ count rates ranging from $\sim 4 \times 10^{5}$ to $1.2 \times 10^{6}$. Although the absolute value of the dead-time depends on the type and age of the electron multiplier (we have earlier obtained a value of $19 \pm 1$ nanosec (Goswami et al 1991) with a new electron multiplier), the dead-time of the counting system generally remains stable for periods of a few weeks to a couple of months. As an added precaution, the maximum count rate during isotopic analysis is generally kept below $2 \times 10^{5} \mathrm{c} / \mathrm{s}$ so that possible errors in the measured isotopic ratios due to uncertainty in the dead time of the counting system is much less than the limit set by counting statistics, which is typically $2 \%\left(2 \sigma_{m}\right)$. The background of the counting system is $\sim 0.005 \mathrm{c} / \mathrm{s}$ in the static mode of operation, and is somewhat higher $(\leqslant 0.01 \mathrm{c} / \mathrm{s})$ in the dynamic (peak-jumping) mode. Since the count rates during isotopic measurements generally exceed $100 \mathrm{c} / \mathrm{s}$, this background is negligible. The efficiency of the electron multiplier (EM) is deduced by comparing the dead-time corrected count rate obtained by the EM with the background corrected count rate obtained with the faraday cup which is assumed to have a counting efficiency of unity. The EM efficiency is typically $\geqslant 75 \%$ and it is replaced when this value reaches $\sim 70 \%$. All the counting system parameters (background, efficiency and dead-time) are checked periodically to monitor possible shifts in their values.

\subsection{Isotopic measurements of standards}

We have analyzed a set of terrestrial minerals as standards for their magnesium and titanium isotopic compositions to check the precision and reproducibility of our ion microprobe measurements. In addition, a set of anorthositic glasses doped with known amounts of ${ }^{25} \mathrm{Mg}$ were also analyzed. These glasses were also used as internal standards by two other ion microprobe laboratories (Armstrong et al 1982; McKeegan et al 1985).

The measured isotopic ratios in the standards generally differ from the reference values due to mass fractionation effects caused by the processes involved in the production and extraction of the analyzed ions, the so-called instrument mass fractionation effect. However, if an element has more than two isotopes, the mass 
Table 1. $\mathrm{Mg}$ isotopic data for terrestrial standardse.

\begin{tabular}{lcrrr}
\hline Sample & $\mathrm{N}^{*}$ & $\begin{array}{c}{ }^{27} \mathrm{Al} /{ }^{24} \mathrm{Mg} \\
\pm 2 \sigma_{m}\end{array}$ & \multicolumn{1}{c}{$\begin{array}{c}\Delta^{25} \mathrm{Mg}_{\mathrm{g}} \\
\pm 2 \sigma_{m}\end{array}$} & \multicolumn{1}{c}{$\begin{array}{c}\delta^{26} \mathrm{Mg}_{\mathrm{g}} \\
\pm 2 \sigma_{m}\end{array}$} \\
\hline Burma Spinel $^{\mathrm{d}}$ & 4 & $2.59 \pm 0.01$ & $-11.62 \pm 0.59$ & $-2.04 \pm 1.14$ \\
Spinel $^{\mathrm{b}}$ & 5 & $2.60 \pm 0.02$ & $-12.41 \pm 0.66$ & $-1.67 \pm 1.28$ \\
Melilite $^{b}$ & 6 & $1.32 \pm 0.01$ & $-7.81 \pm 0.48$ & $-0.60 \pm 0.88$ \\
Madagascar Hibonite $^{\mathrm{c}}$ & 4 & $30.8 \pm 1.50$ & $-5.80 \pm 0.84$ & $1.25 \pm 1.73$ \\
Lake County Plagioclased $^{d}$ & 2 & $215.76 \pm 8 \cdot 10$ & $-6.28 \pm 1.90$ & $0.72 \pm 3.64$
\end{tabular}

- Number of repeat measurements.

'Vernadsky Institute, Moscow.

${ }^{\circ} \mathrm{H}$ Curien et al (1956).

${ }^{4}$ National Museum of Natural History, Smithsonian Institution, Washington, D C

${ }^{4} \Delta^{25} \mathrm{Mg}$ and $\delta^{26} \mathrm{Mg}$ values are in permil.

fractionation effect can be determined by using one of the measured isotopic ratios as an initial standard. The other measured isotopic ratios can then be corrected for mass fractionation effect using an appropriate mass fractionation law.

In presenting our results of isotopic measurements, we shall be using the following notations:

and

$$
\Delta^{M_{j}}=\left[\frac{\left(M_{j} / M_{i}\right)_{m}}{\left(M_{j} / M_{i}\right)_{r}}-1\right] \times 1000 \quad(\%)
$$

$$
\delta^{M_{k}}=\Delta^{M_{k}}-F \cdot \Delta^{M_{j}} \quad(\%)
$$

where $M_{j}, M_{j}, M_{k}$ are the different isotopes of the element $M, m$ and $r$ refer to measured and reference values for the isotopic ratios, $\Delta^{M_{1}}$ is the magnitude of mass fractionation (in per mil) for the isotope $M_{j}$ with $M_{j}$ as the reference isotope, $\delta^{M_{k}}$ is the fractionation corrected residual (in per mil) for the isotopic ratio $\mathbf{M}_{\mathbf{k}} / \mathbf{M}_{\mathbf{i}}$ and $F$ is a factor that depends on the mass fractionation law used for fractionation correction. $\delta^{\mathbf{M}_{\mathbf{j}}}$ is zero by definition and $\delta^{\mathbf{M}_{\mathbf{k}}}$ should be zero, within experimental uncertainties, for terrestrial standards.

We show in table 1, the results from our magnesium isotopic studies of a set of terrestrial minerals used as standards. These measurements were carried out at a mass resolution of $\sim 4,000$, sufficient to resolve the hydride and other isobaric interferences. The minerals chosen can be considered as terrestrial analogs of the refractory meteoritic phases from the Ca-Al-rich inclusions (CAIs) analyzed for their isotopic compositions (see next section). The values of $\Delta^{25} \mathrm{Mg}$ (with ${ }^{24} \mathrm{Mg}$ as the reference isotope) represent the magnitude of magnesium isotopic mass fractionation (\%o/amu) for the different mineral species. The $\delta^{26} \mathrm{Mg}$ values for the different mineral phases were obtained by assuming a linear mass fractionation relation $\left(\delta^{26} \mathrm{Mg}=\Delta^{26} \mathrm{Mg}-2 \Delta^{25} \mathrm{Mg}\right)$ and the values are generally consistent with zero within the limits of our experimental uncertainties.

In table 2, we show the results obtained from titanium isotopic measurements in Ti-metal and terrestrial perovskite and hibonite. Both the terrestrial minerals contain $\mathrm{Ca}$ and $\mathrm{Ti}$ and the measurements were made at a mass-resolution $(\mathrm{M} / \Delta \mathrm{M})$ exceeding 10,000 ; to resolve the isobaric interference of ${ }^{48} \mathrm{Ca}$ at ${ }^{48} \mathrm{Ti}$ (see figure 3 ). Since ${ }^{46} \mathrm{Ti}$ 


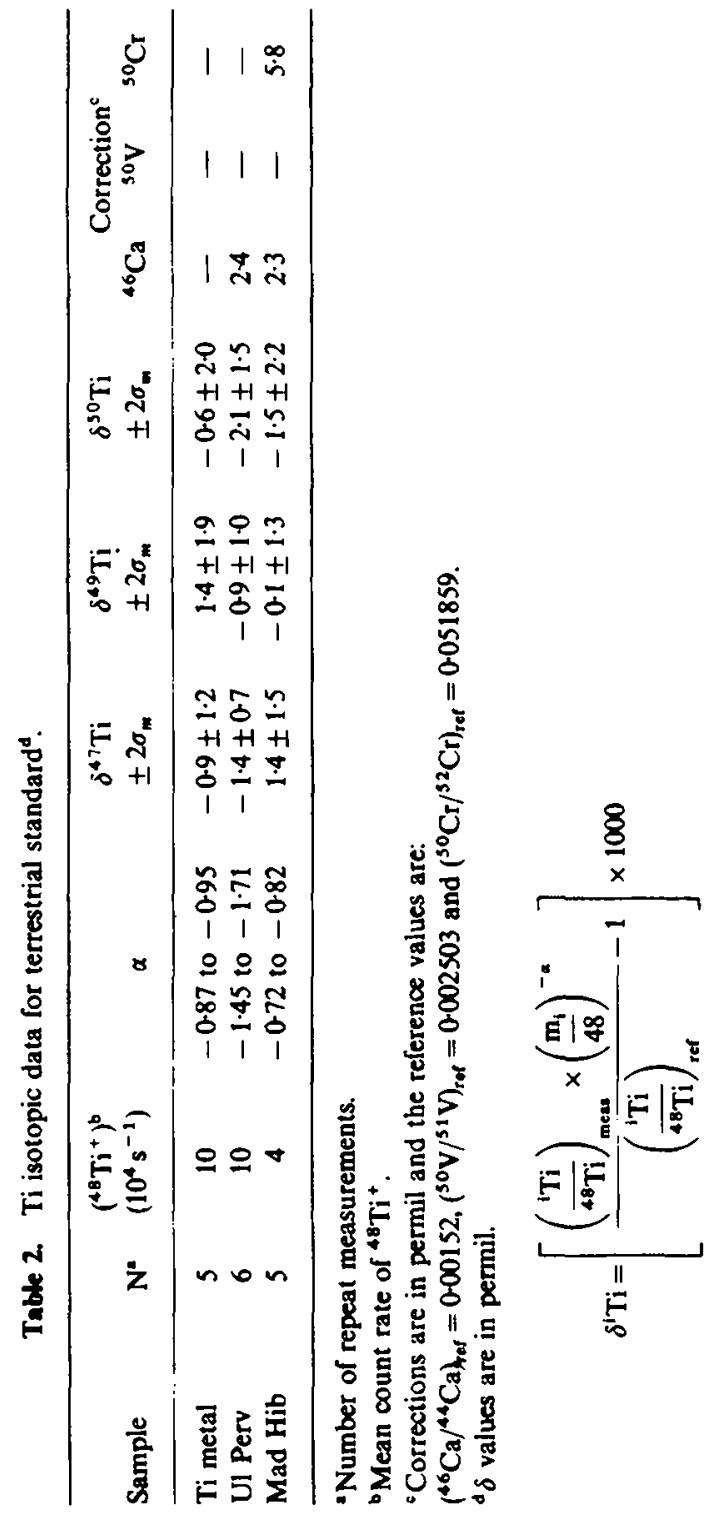


and ${ }^{46} \mathrm{Ca}$ cannot be resolved at this mass resolution, the contribution from ${ }^{46} \mathrm{Ca}$ to ${ }^{46} \mathrm{Ti}$ was estimated by monitoring count rate at ${ }^{44} \mathrm{Ca}$ and assuming normal calcium isotopic abundances. In addition, if $\mathrm{Cr}$ and $\mathrm{V}$ are present, the unresolved isobaric interferences at ${ }^{30} \mathrm{Ti}$ from ${ }^{50} \mathrm{Cr}$ and ${ }^{50} \mathrm{~V}$ are corrected by monitoring the count rates of the most abundant isotopes of $\mathrm{Cr}\left({ }^{52} \mathrm{Cr}\right)$ and $\mathrm{V}\left({ }^{51} \mathrm{~V}\right)$ and estimating the correction needed at mass 50 , assuming normal $\mathrm{Cr}$ and $\mathrm{V}$ isotopic abundances. An exponential mass fractionation law was used for analyzing the titanium isotopic data as it describes the instrument mass fractionation effect better (e.g. see Fahey et al 1987). (Note that because of the small mass range of the magnesium isotopes (24-26), the linear approximation describes the fractionation effect adequately and the use of an exponential law will change the $\delta^{26} \mathrm{Mg}$ values in table 1 by less than $0: 3 \%$ ). ${ }^{46} \mathrm{Ti}$ and ${ }^{48} \mathrm{Ti}$ are used as the reference isotopes for determining the magnitude of isotopic mass fractionation given by the parameter ' $\alpha$ ' defined as:

$$
\frac{\left({ }^{46} \mathrm{Ti} /{ }^{48} \mathrm{Ti}\right)_{m}}{\left({ }^{46} \mathrm{Ti} /{ }^{48} \mathrm{Ti}\right)_{r}}=\left(\frac{46}{48}\right)^{-\alpha}
$$

The data shown in table 2 clearly indicate that the $\delta$ values for the titanium isotopic ratios are generally consistent with zero within the limits of our experimental uncertainties. Thus, our ion microprobe provides reliable estimates of isotopic ratios, both at medium and high mass resolutions ( $M / \Delta M$ values ranging from 4,000 to $10,000)$, with a precision of $\sim 2$ to $3 \%\left(2 \sigma_{m}\right)$.

The magnitude of isotopic mass fractionation for a given element varies with the composition of the sample matrix and also depends on the instrument operating conditions. However, for a particular instrument operating condition and a given sample matrix it should be possible to obtain reproducible results. We show in figure 6 the values for magnesium isotopic mass fractionation $\left(\Delta^{25} \mathrm{Mg}\right)$ in terrestrial spinel measured at different times during a 24 hour run. All values cluster within $1 \%$ of the mean value of $11.7 \%$ indicating very good reproducibility of the magnitude of isotopic mass fractionation under a given instrument operating condition.

The measured magnesium isotopic compositions in the isotopically spiked anorthositic glasses are shown in table 3 . The results obtained by us are in agreement with those obtained by the Caltech (PUNURGE) and Washington University (WU)

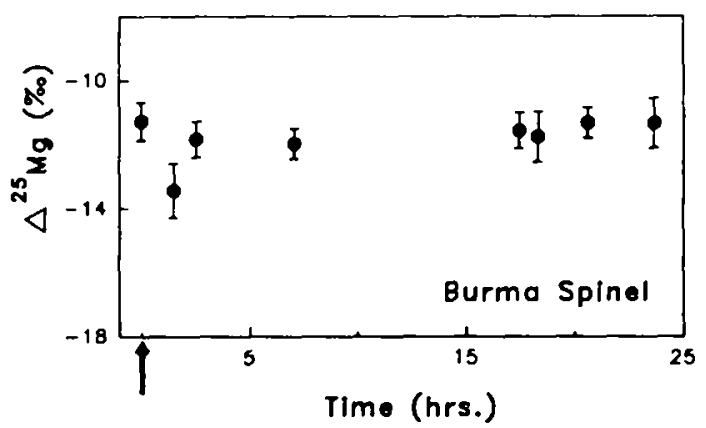

Figure 6. Magnesium isotopic mass-fractionation in terrestrial spinel obtained from repeated analysis during a 24 hour run period. The arrow marks the start of the run. Error bars are $2 \sigma_{m}$. 
Table 3. Mg composition of isotopically spiked glasses".

\begin{tabular}{lrrrrr}
\hline Sample & & \multicolumn{5}{c}{$\delta^{25} \mathrm{Mg}^{\circ}\left( \pm 2 \sigma_{m}\right)$} \\
\cline { 3 - 6 } & ppm & \multicolumn{1}{c}{ Grav } & \multicolumn{1}{c}{ PRL } & \multicolumn{1}{c}{ Panurge $^{c}$} & \multicolumn{1}{c}{ WU $^{d}$} \\
\hline AN-MG-1 & 292 & 0.0 & $0.3 \pm 2.7$ & $3.3 \pm 3.4$ & $1.9 \pm 1.6$ \\
AN-MG-2 & 292 & 29.2 & $28.8 \pm 1.9$ & $31.4 \pm 5.4$ & $29.5 \pm 1.6$ \\
AN-MG-3 & 292 & 101.7 & $100.8 \pm 2.8$ & $101.2 \pm 4.7$ & $99.2 \pm 1.6$ \\
AN-MG-4 & 292 & 318.0 & $307.2 \pm 2.5$ & $310.0 \pm 3.7$ & $315.8 \pm 1.7$ \\
AN-MG-5 & 1000 & 0.0 & $0.7 \pm 1.8$ & $2.2 \pm 2.9$ & $0.7 \pm 2.2$ \\
AN-MG-6 & 1000 & 9.4 & $9.8 \pm 1.7$ & $9.1 \pm 2.3$ & $9.2 \pm 1.5$ \\
AN-MG-7 & 1000 & 28.9 & $29.7 \pm 2.7$ & $29.6 \pm 4.8$ & $30.4 \pm 1.9$ \\
AN-MG-8 & 1000 & 97.9 & $96.9 \pm 2.2$ & $96.7 \pm 2.1$ & $97.5 \pm 1.9$
\end{tabular}

$\cdot \delta^{25} \mathrm{Mg}=\Delta^{25} \mathrm{Mg}-0.5 \cdot \Delta^{26} \mathrm{Mg}$.

${ }^{b}$ Gravimetric measurement.

' Panurge (IMS-3F at Caltech): J T Armstrong et al (1982).

dWU (IMS-3F at Washington Univ.): K D McKeegan et al (1985).

e $\delta^{25} \mathrm{Mg}$ values are in permil.

groups using modified Cameca IMS-3f ion microprobes and are also close to the gravimetric values. A small difference can be noticed for the sample (AN-MG-4) with the highest $\delta^{25} \mathrm{Mg}$ value. Note that all the ion microprobe numbers for this sample are lower than the gravimetric value. This perhaps reflects a small degree of heterogeneity in this sample. The results shown in table 3 clearly demonstrate that we can achieve a precision of $\pm 2 \%_{0}\left(2 \sigma_{m}\right)$ in magnesium isotopic measurements even in samples with very small magnesium concentration (a few hundred ppm). Overall, the results from isotopic measurements of standards presented in this section show that reliable and high-precision isotopic measurements can be made using our ion microprobe at mass resolutions ranging from 4,000 to 10,000 . In the next section, we discuss some of the results we have obtained from measurements of magnesium, calcium and potassium isotopic compositions in different mineral phases of several $\mathrm{Ca}-\mathrm{Al}$-rich refractory inclusions (CAIs) from two primitive meteorites. As noted in the introduction, the CAIs are considered to be some of the earliest objects to have formed in the solar system.

\section{Isotopic studies of early solar system objects}

We have analyzed magnesium, calcium and potassium isotopic compositions in a set of CAIs isolated from two primitive carbonaceous chondrites: Efremovka and Grosnaja. Petrographic and trace element studies (Ulyanov et al 1982; Nazarov et al 1982; see also Goswami et al 1994) of Efremovka CAIs show them to be very pristine solar system objects. The Grosnaja CAIs on the other hand show clear signs of secondary alterations which are evident from the presence of secondary lowtemperature minerals like calcite, garnet, $\mathrm{Na}$-rich plagioclase etc. within the refractory mineral assemblage. Here we discuss the results of isotopic studies of six CAIs from these two meteorites. Results obtained from petrographic and isotopic studies of additional CAIs from these meteorites are reported elsewhere (Goswami et al 1993a, b, 1994; Srinivasan et al 1993a, b). 
Magnesium isotopic studies of the CAIs were carried out primarily to look for the possible presence of excess ${ }^{26} \mathrm{Mg}$ [i.e. $\delta^{26} \mathrm{Mg}>0$; see relation (2)], resulting from the decay of the now-extinct nuclide ${ }^{26} \mathrm{Al}\left(t_{1 / 2}=7 \times 10^{5} \mathrm{yr}\right)$ that could have been present in the early solar system at the time of formation of the CAIs. We have also measured the isotopic composition of potassium in several Efremovka CAIs with ${ }^{26} \mathrm{Mg}$ excess,

Table 4. Mg-Al Data.

\begin{tabular}{cccr}
\hline & $\left({ }^{26} \mathrm{Mg} /{ }^{24} \mathrm{Mg}\right)$ & $\left({ }^{27} \mathrm{Al} / /^{24} \mathrm{Mg}\right)$ & $\delta^{26} \mathrm{Mg}^{*}$ \\
Phase & $\pm 2 \sigma_{m}$ & $\pm 2 \sigma_{m}$ & $\pm 2 \sigma_{m}$
\end{tabular}

Efremovka CAIs

ESO (Multizoned-Hibonite Rich)

\begin{tabular}{lllr}
\hline Melilite 1 & $0.13996 \pm 38$ & $21.37 \pm 0.11$ & $4.57 \pm 2.72$ \\
Melilite 2 & $0.14197 \pm 62$ & $23.69 \pm 0.06$ & $19.02 \pm 4.42$ \\
Melilite 3 & $0.14007 \pm 45$ & $19.69 \pm 0.11$ & $5.37 \pm 3.22$ \\
Melilite 4 & $0.14110 \pm 55$ & $32.56 \pm 3.36$ & $12.76 \pm 3.98$ \\
Melilite 5 & $0.14037 \pm 62$ & $23.86 \pm 0.09$ & $7.56 \pm 4.46$ \\
Melilite 6 & $0.13996 \pm 56$ & $18.86 \pm 0.15$ & $4.58 \pm 4.04$ \\
Melilite 7 & $0.14090 \pm 47$ & $24.25 \pm 0.28$ & $11.37 \pm 3.38$ \\
Melilite 8 & $0-13992 \pm 38$ & $19.62 \pm 0.37$ & $4.30 \pm 2.74$ \\
Melilite 9 & $0-14132 \pm 62$ & $50.60 \pm 0.22$ & $14.38 \pm 4.44$ \\
\hline Spinel 1 & $0.13935 \pm 31$ & $2.59 \pm 0.27$ & $0.24 \pm 2.22$ \\
Spinel 2 & $0.13948 \pm 23$ & $2.60 \pm 0.01$ & $1.17 \pm 1.67$ \\
Spinel 3 & $0.13926 \pm 28$ & $2.62 \pm 0.01$ & $-0.42 \pm 1.99$ \\
Spinel 4 & $0.13952 \pm 33$ & $2.70 \pm 0.03$ & $1.41 \pm 2.38$ \\
\hline Hibonite 1 & $0.14031 \pm 31$ & $17.94 \pm 0.03$ & $7.08 \pm 2.20$ \\
Hibonite 2 & $0.14008 \pm 33$ & $15 \cdot 16 \pm 0.07$ & $5.49 \pm 2.38$ \\
\hline
\end{tabular}

E59 (Type A)

\begin{tabular}{llll}
\hline Melilite 1 & $0.14035 \pm 30$ & $21 \cdot 9 \pm 0.2$ & $7 \cdot 38 \pm 2 \cdot 24$ \\
Melilite 2 & $0.13984 \pm 30$ & $16 \cdot 7 \pm 0.2$ & $3.75 \pm 2.08$ \\
Melilite 3 & $0.14016 \pm 34$ & $18 \cdot 1 \pm 0.2$ & $6.03 \pm 2 \cdot 40$ \\
Melilite 4 & $0.13977 \pm 30$ & $12 \cdot 1 \pm 0.2$ & $3.24 \pm 2 \cdot 20$ \\
Melilite 5 & $0.14024 \pm 44$ & $15.9 \pm 0.2$ & $6.57 \pm 3 \cdot 10$ \\
Melilite 6 & $0.14044 \pm 64$ & $23.7 \pm 0.2$ & $8.04 \pm 4.60$ \\
Melilite 7 & $0.14050 \pm 40$ & $34.0 \pm 0.2$ & $8.44 \pm 2.92$ \\
\hline
\end{tabular}

E36 (Type B2)

\begin{tabular}{lrrr}
\hline Melilite 1 & $0-13976 \pm 27$ & $12.38 \pm 0.20$ & $3.27 \pm 1.97$ \\
Melilite 2 & $0-13949 \pm 34$ & $8.52 \pm 0.10$ & $1.20 \pm 2.40$ \\
Melilite 3 & $0.13909 \pm 12$ & $3.50 \pm 0.01$ & $-1.61 \pm 0.87$ \\
Melilite 4 & $0.13987 \pm 26$ & $13.08 \pm 0.28$ & $3.97 \pm 1.92$ \\
Melilite 5 & $0-13980 \pm 22$ & $11.28 \pm 0.36$ & $3.47 \pm 1.60$ \\
Melilite 6 & $0.13961 \pm 14$ & $4.96 \pm 0.28$ & $2.08 \pm 1.02$ \\
Melilite 7 & $0.13976 \pm 22$ & $6.04 \pm 0.16$ & $3.22 \pm 1.60$ \\
Melilite 8 & $0.13954 \pm 30$ & $2.00 \pm 0.06$ & $1.55 \pm 2.22$ \\
\hline
\end{tabular}


Table 4. (Continued)

\begin{tabular}{|c|c|c|c|}
\hline Phase & $\begin{array}{c}\left({ }^{26} \mathrm{Mg} /{ }^{24} \mathrm{Mg}\right) \\
\pm 2 \sigma_{m}\end{array}$ & $\begin{array}{c}\left({ }^{27} \mathrm{Al} / /^{24} \mathrm{Mg}\right) \\
\pm 2 \sigma_{m}\end{array}$ & $\begin{array}{c}\delta^{26} \mathrm{Mg}^{*} \\
\pm 2 \sigma_{m}\end{array}$ \\
\hline $\begin{array}{l}\text { Melilite } 9 \\
\text { Melilite } 10\end{array}$ & $\begin{array}{l}0 \cdot 13984 \pm 32 \\
0 \cdot 13959 \pm 28\end{array}$ & $\begin{array}{l}21 \cdot 52 \pm 0.80 \\
17.33 \pm 0.60\end{array}$ & $\begin{array}{l}3 \cdot 70 \pm 2 \cdot 34 \\
1.92 \pm 2 \cdot 00\end{array}$ \\
\hline Fassaite 1 & $0 \cdot 13919 \pm 30$ & $1.72 \pm 0.02$ & $-0.92 \pm 2.16$ \\
\hline \multicolumn{4}{|c|}{ Grosnaja CAIs } \\
\hline \multicolumn{4}{|c|}{ GR4 (Type A) } \\
\hline $\begin{array}{l}\text { Melilite } 1 \\
\text { Melilite } 2 \\
\text { Melilite } 3 \\
\text { Melilite } 4 \\
\text { Melilite } 5 \\
\text { Melilite } 6 \\
\text { Melilite } 7 \\
\text { Melilite } 8 \\
\text { Melilite } 9 \\
\text { Melilite } 10\end{array}$ & $\begin{array}{l}0 \cdot 13979 \pm 31 \\
0 \cdot 13978 \pm 25 \\
0 \cdot 14034 \pm 50 \\
0 \cdot 13950 \pm 46 \\
0 \cdot 13979 \pm 52 \\
0 \cdot 13960 \pm 48 \\
0 \cdot 13920 \pm 26 \\
0 \cdot 13960 \pm 52 \\
0 \cdot 13937 \pm 40 \\
0 \cdot 13974 \pm 40\end{array}$ & $\begin{array}{r}7.4 \pm 0.04 \\
6.1 \pm 0.05 \\
11 \cdot 1 \pm 0.15 \\
8.8 \pm 0.04 \\
12.2 \pm 0.04 \\
12.1 \pm 0.13 \\
5.0 \pm 0.13 \\
27.5 \pm 0.40 \\
10.9 \pm 0.05 \\
14.6 \pm 0.60\end{array}$ & $\begin{array}{r}3.4 \pm 2.2 \\
3.3 \pm 1.8 \\
7.3 \pm 3.6 \\
1.3 \pm 3.3 \\
3.4 \pm 3.7 \\
2.0 \pm 3.4 \\
-0.9 \pm 2.6 \\
2.0 \pm 3.8 \\
0.3 \pm 2.9 \\
3.0 \pm 2.9\end{array}$ \\
\hline Spinel 1 & $0 \cdot 13977 \pm 33$ & $2 \cdot 5 \pm 0.003$ & $3 \cdot 2 \pm 2 \cdot 4$ \\
\hline \multicolumn{4}{|c|}{ GR7 (Type B) } \\
\hline $\begin{array}{l}\text { Melilite } 1 \\
\text { Melilite } 2 \\
\text { Melilite } 3 \\
\text { Melilite } 4 \\
\text { Melilite } 5 \\
\text { Melilite } 6 \\
\text { Melilite } 7 \\
\text { Melilite } 8 \\
\text { Melilite } 9 \\
\text { Melilite } 10\end{array}$ & $\begin{array}{l}0.13937 \pm 42 \\
0.13992 \pm 64 \\
0.13959 \pm 58 \\
0 \cdot 13922 \pm 60 \\
0 \cdot 13987 \pm 62 \\
0 \cdot 13967 \pm 84 \\
0 \cdot 13920 \pm 56 \\
0.13952 \pm 70 \\
0 \cdot 13995 \pm 72 \\
0 \cdot 13986 \pm 60\end{array}$ & $\begin{array}{r}1.44 \pm 0.01 \\
1.92 \pm 0.02 \\
3.55 \pm 0.03 \\
4.16 \pm 0.07 \\
3.35 \pm 0.02 \\
3.21 \pm 0.01 \\
9.44 \pm 0.80 \\
5.44 \pm 0.05 \\
15.31 \pm 1.02 \\
13.76 \pm 1.22\end{array}$ & $\begin{array}{r}0.36 \pm 1.54 \\
4.32 \pm 2.32 \\
1.94 \pm 2.08 \\
3.98 \pm 2.26 \\
2.51 \pm 3.02 \\
-0.85 \pm 1.99 \\
1.45 \pm 2.54 \\
2.38 \pm 1.80 \\
4.51 \pm 2.56 \\
3.88 \pm 2.14\end{array}$ \\
\hline \multicolumn{4}{|c|}{ GR2 (Type C) } \\
\hline $\begin{array}{l}\text { Anorthite } 1 \\
\text { Anorthite } 2 \\
\text { Anorthite } 3 \\
\text { Anorthite } 4 \\
\text { Anorthite } 5 \\
\text { Anorthite } 6\end{array}$ & $\begin{array}{l}0 \cdot 14108 \pm 65 \\
0 \cdot 14048 \pm 33 \\
0 \cdot 14025 \pm 71 \\
0 \cdot 14049 \pm 65 \\
0 \cdot 14055 \pm 71 \\
0 \cdot 14038 \pm 10\end{array}$ & $\begin{array}{l}360 \cdot 1 \pm 30 \cdot 1 \\
354 \cdot 8 \pm 11 \cdot 0 \\
317 \cdot 1 \pm 2 \cdot 6 \\
321 \cdot 5 \pm 3 \cdot 5 \\
647 \cdot 4 \pm 64 \cdot 1 \\
318.7 \pm 2 \cdot 08\end{array}$ & $\begin{array}{r}12 \cdot 6 \pm 4 \cdot 7 \\
8.3 \pm 2.4 \\
6 \cdot 7 \pm 5 \cdot 1 \\
8 \cdot 4 \pm 4 \cdot 7 \\
8 \cdot 8 \pm 5 \cdot 1 \\
7 \cdot 6 \pm 0.7\end{array}$ \\
\hline $\begin{array}{l}\text { Fassaite } 1 \\
\text { Fassaite } 2 \\
\text { Fassaite } 3 \\
\text { Fassaite } 4 \\
\text { Fassaite } 5 \\
\text { Fassaite } 6\end{array}$ & $\begin{array}{l}0 \cdot 13933 \pm 32 \\
0 \cdot 13940 \pm 29 \\
0 \cdot 13933 \pm 32 \\
0 \cdot 13946 \pm 39 \\
0 \cdot 13963 \pm 42 \\
0 \cdot 13938 \pm 24\end{array}$ & $\begin{array}{l}2.0 \pm 0.003 \\
0.8 \pm 0.001 \\
0.7 \pm 0.001 \\
2.1 \pm 0.004 \\
7 \cdot 2 \pm 0.004 \\
2.0 \pm 0.002\end{array}$ & $\begin{array}{l}0.1 \pm 2.3 \\
0.6 \pm 2.1 \\
0.1 \pm 2.3 \\
1.0 \pm 2.8 \\
2.2 \pm 3.0 \\
0.4 \pm 1.7\end{array}$ \\
\hline
\end{tabular}

${ }^{*} \delta^{26} \mathrm{Mg}$ is in permil. 
to look for possible excess in ${ }^{41} \mathrm{~K}$ due to the decay of ${ }^{41} \mathrm{Ca}\left(t_{1 / 2} \sim 10^{5} \mathrm{yr}\right)$. Presence or absence of excess ${ }^{26} \mathrm{Mg}$ and ${ }^{41} \mathrm{~K}$ in the CAIs allows us to constrain the time interval between the last addition of freshly synthesized matter to the solar nebula and formation of some of the first solar system solids (CAIs). These studies also allow us to deduce the aluminium and calcium isotopic ratios $\left[{ }^{26} \mathrm{Al} /{ }^{27} \mathrm{Al}\right.$ and $\left.{ }^{41} \mathrm{Ca} /{ }^{40} \mathrm{Ca}\right]$ at the time of formation of the CAIs and address the question of isotopic homogeneity or lack of it in the solar nebula in the region of CAI formation.

\subsection{Magnesium isotopic composition}

We show in table 4, the measured values of magnesium isotopic compositions in different refractory mineral phases of three Efremovka and three Grosnaja CAIs. The tabulated ${ }^{26} \mathrm{Mg} /{ }^{24} \mathrm{Mg}$ values are corrected for fractionation effect based on the measured ${ }^{25} \mathrm{Mg} /{ }^{24} \mathrm{Mg}$ ratios using a linear mass fractionation relation. It is obvious that the ${ }^{26} \mathrm{Mg} /{ }^{24} \mathrm{Mg}$ in many samples, particularly for the Efremovka CAIs, are in excess of the reference value of 0.13932 . The magnitude of this excess is given by the tabulated value of $\delta^{26} \mathrm{Mg}$. Also shown in the table are the measured ${ }^{27} \mathrm{Al} /{ }^{24} \mathrm{Mg}$ in each case.

In figure 7, we show plots of measured ${ }^{26} \mathrm{Mg} /{ }^{24} \mathrm{Mg}$ values as a function of ${ }^{27} \mathrm{Al} /{ }^{24} \mathrm{Mg}$, the so-called $\mathrm{Mg}-\mathrm{Al}$ evolution diagrams, for the three Efremovka CAIs (E36, E50 and E59) and one of the Grosnaja CAIs (GR2) having excess ${ }^{26} \mathrm{Mg}$. Since this excess suggests the presence of a radiogenic ${ }^{26} \mathrm{Mg}$ component, one can write:

$$
\begin{aligned}
{\left[{ }^{26} \mathrm{Mg} /{ }^{24} \mathrm{Mg}\right]_{m} } & =\left[{ }^{26} \mathrm{Mg} /{ }^{24} \mathrm{Mg}\right]_{i}+\left[{ }^{26} \mathrm{Mg} * /{ }^{24} \mathrm{Mg}\right] \\
& =\left[{ }^{26} \mathrm{Mg} /{ }^{24} \mathrm{Mg}\right]_{i}+\left[{ }^{26} \mathrm{Al} /{ }^{27} \mathrm{Al}\right]_{i} \times\left[{ }^{27} \mathrm{Al} /{ }^{24} \mathrm{Mg}\right]_{\mathrm{m}}
\end{aligned}
$$

where $m$ and $i$ refer to measured and initial values of the isotopic ratios and the "*' denotes the radiogenic component. The intercept and the slope of the $\mathrm{Mg}-\mathrm{Al}$ evolution diagrams, defined by the above relation, provide the values of the initial magnesium and aluminium isotopic compositions at the time of formation of the CAIs. These values based on least square fit to the data are also shown in figure 7. The very good correlation of excess ${ }^{26} \mathrm{Mg}$ with ${ }^{27} \mathrm{Al}$ in the Efremovka CAIs E50 and E59 suggests that this excess resulted from in situ decay of ${ }^{26} \mathrm{Al}$ that was incorporated 'live' into the CAIs at the time of their formation. The correlation in the case of Efremovka CAI E36 is not as good and although the data suggest the presence of radiogenic

${ }^{26} \mathrm{Mg}$ with an initial aluminium isotopic ratio close to the values obtained for the other two Efremovka CAIs, we cannot completely rule out the possibility of some disturbances in the magnesium isotopic systematics in melilite of this CAI. The results from the Grosnaja CAI (GR2) [table 4; figure 7(d)] show a different trend. Although excess ${ }^{26} \mathrm{Mg}$ is present, the initial ${ }^{26} \mathrm{Al} /{ }^{27} \mathrm{Al}$ is much lower than those for Efremovka CAIs, and several data points deviate from the correlation line. The $\mathbf{M g}-\mathbf{A l}$ data for the other two Grosnaja CAIs (see table 4) yield even lower initial ${ }^{26} \mathrm{Al} /{ }^{27} \mathrm{Al}$ at the time of their formation. In fact, the data for GR4 is consistent with absence of ${ }^{26} \mathrm{Al}$ (no excess ${ }^{26} \mathrm{Mg}$ ) and hence a zero value for this ratio. The observed features in the Grosnaja CAIs are suggestive of late disturbances in the $\mathbf{M g}-\mathbf{A l}$ systematics of these objects. This is strengthened by the petrographic evidence for secondary alterations in the Grosnaja CAIs [presence of secondary minerals (e.g. calcite, garnet, Na-rich plagioclase) in an otherwise refractory mineral assemblage]. Earlier studies of 
magnesium isotopic composition in CAIs (MacPherson et al 1988 and references therein) indeed showed that the inferred values of initial ${ }^{26} \mathrm{Al} /{ }^{27} \mathrm{Al}$ in CAIs vary over a wide range $\left(0\right.$ to $\left.\sim 5 \times 10^{-5}\right)$. This observation led to the generally accepted suggestion of an extremely heterogeneous distribution of ${ }^{26} \mathrm{Al}$ in the solar nebula. We however feel that the variations in the initial ratio are a reflection of secondary processes affecting the CAIs and do not necessarily imply a heterogeneity in the distribution of ${ }^{26} \mathrm{Al}$. It can be seen that seven of the eight petrographically unaltered CAIs from the Efremovka meteorite that we have analyzed for their magnesium
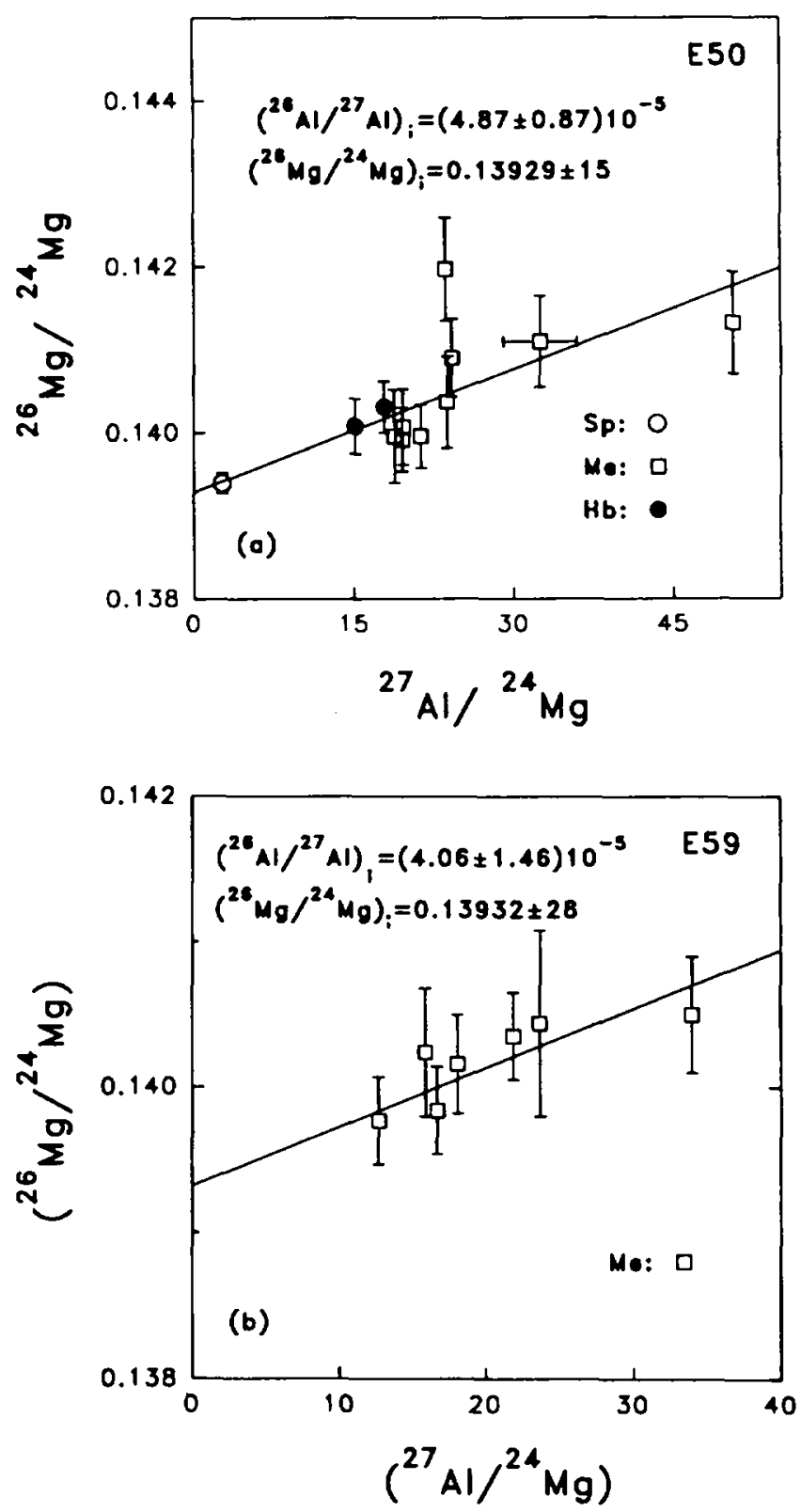

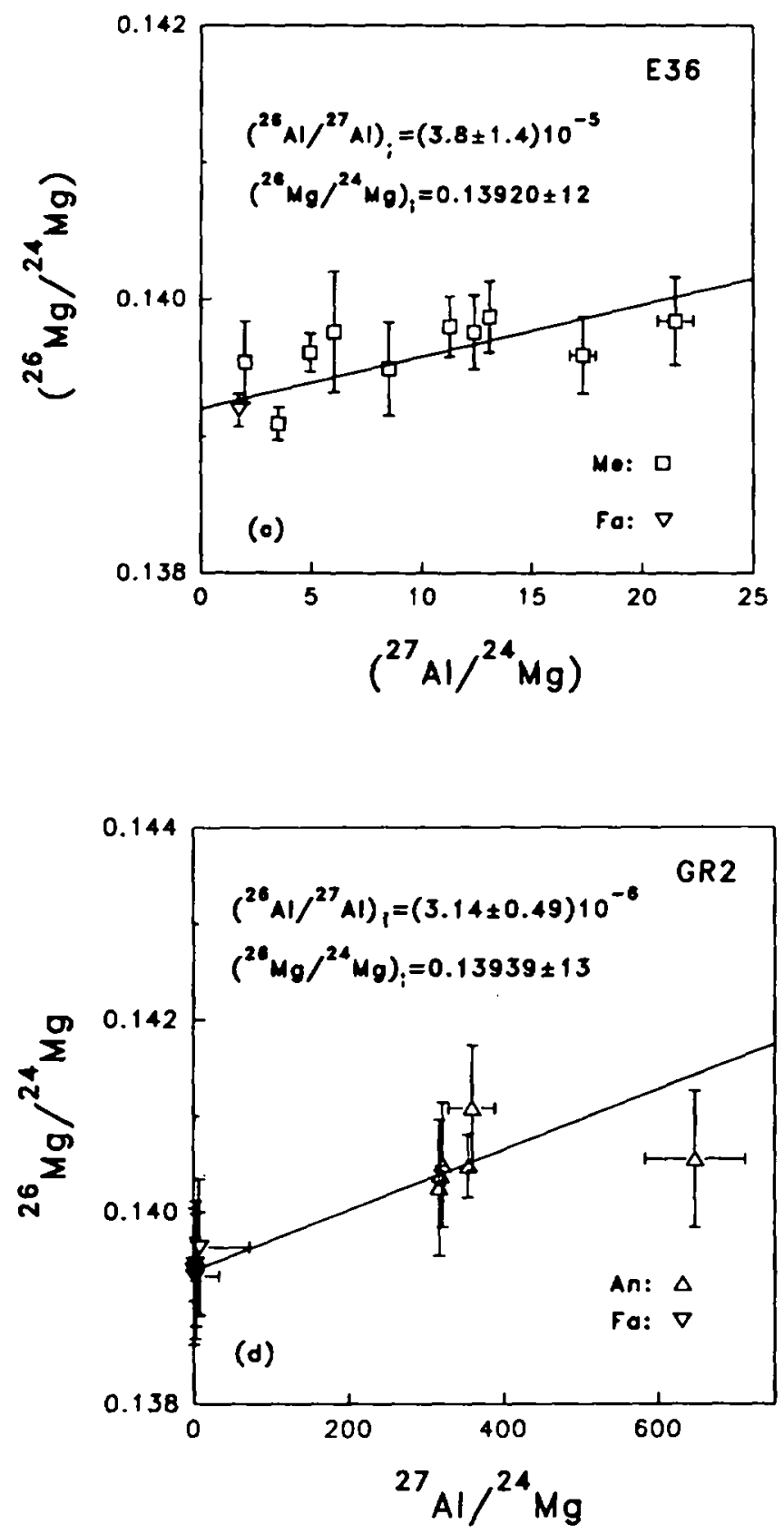

Figure 7. Mg-Al evolution diagrams for the Efremovka CAIs E50 (figure 7a), E59 (figure 7b), E36 (figure 7c) and the Grosnaja CAI GR2 (figare 7d). The different mineral phases analyzed are: spinel ( $\mathrm{Sp}$ ), melilite (Me), pyroxene (fassaite: $\mathrm{Fa}$ ), anorthite ( $\mathrm{An}$ ) and hibonite (Hb). Errors for all the data points and initial ratios are $2 \sigma_{m}$. 


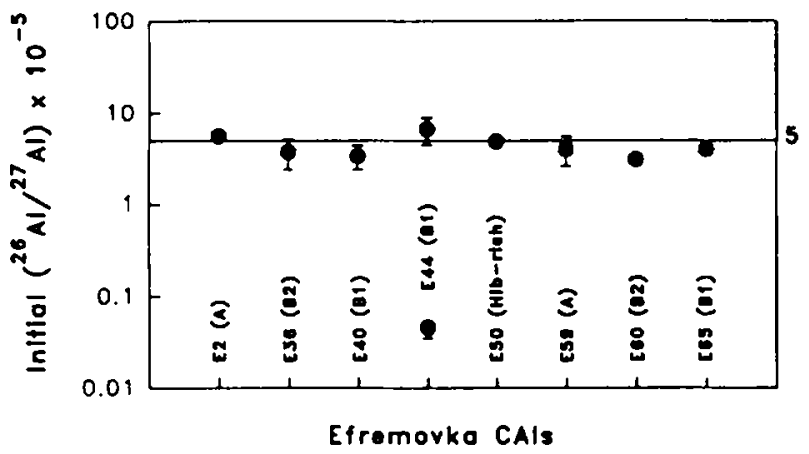

Figure 8. Initial ${ }^{26} \mathrm{Al} /{ }^{27} \mathrm{Al}$ in eight petrographically unaltered Efremovka CAIs analyzed for their magnesium isotopic systematics (this work; Goswami et al 1994). The analyzed CAIs represent four different petrologic types (A, B1, B2 and hibonite-rich).

isotopic composition (this work; Goswami et al 1994) have initial ${ }^{26} \mathrm{Al} /{ }^{27} \mathrm{Al}$ clustering around $5 \times 10^{-5}$ (see figure 8). The discordance seen in the case of the type B1 CAI E44, where the two points in figure 8 refer to the slopes of two distinct evolution lines defined by tw.o mineral phases (anorthite and melilite) in this CAI, can be explained in terms of magnesium isotopic exchange between these two phases with contrasting $\mathrm{Al} / \mathrm{Mg}$ ratios (Goswami et al 1994). The analyzed Efremovka CAIs also represent four distinct petrographic types [melilite-rich(A); melilite/pyroxene-rich (B1, B2) and hibonite-rich] and all of them have initial ${ }^{26} \mathrm{Al} /{ }^{27} \mathrm{Al}$ value close to $5 \times 10^{-5}$. In earlier studies of CAIs from other primitive meteorites this value was found primarily in unaltered type B1 CAIs (MacPherson et al 1988 and references therein). On the other hand, the lower initial ${ }^{26} \mathrm{Al} /{ }^{27} \mathrm{Al}$ values are always associated with CAIs that have distinct petrographic signatures of secondary alteration irrespective of their petrologic type (e.g. the Grosnaja CAIs in this study). We, therefore, propose that the distribution of ${ }^{26} \mathrm{Al}$ in the solar nebula in the region of CAI formation was rather uniform, and that the observed variations in the initial value of ${ }^{26} \mathrm{Al} /{ }^{27} \mathrm{Al}$ in many CAIs are due to post-formation processes resulting in reequilibration and/or exchange/redistribution of magnesium isotopes in these objects. A uniform distribution of ${ }^{26} \mathrm{Al}$ in the nebula was also advocated by Podosek et al (1991) who analyzed a set of CAIs from the Allende meteorite with clear petrographic signatures for secondary alterations and by MacPherson et al (1992) who analyzed the literature data on magnesium isotopic systematics for objects with high $\mathrm{Al} / \mathrm{Mg}$ ratios. We must, however, point out that there are certain refractory phases (e.g. hibonite: $\mathrm{CaAl}_{12} \mathrm{O}_{19}$ and corundum: $\mathrm{Al}_{2} \mathrm{O}_{3}$ ) in primitive meteorites that show isotopic anomalies in $\mathrm{O}, \mathrm{Ca}$ and $\mathrm{Ti}$, attesting to their pristine preservation but without excess ${ }^{26} \mathrm{Mg}$ (Fahey et al 1987; Ireland 1990; Virag et al 1991). Thus, although the magnesium isotopic data for most of the CAIs are consistent with a nearly homogeneous distribution of ${ }^{26} \mathrm{Al}$ in the solar nebula, we cannot completely rule out the possibility of more than one distinct reservoir of ${ }^{26} \mathrm{Al}$ in the nebula.

\subsection{Potassium isotopic composition and time scales for early solar system processes}

The presence of ${ }^{26} \mathrm{Al}\left(t_{1 / 2}=7 \times 10^{5} \mathrm{yr}\right)$ in the solar nebula and the value of $5 \times 10^{-5}$ for the initial ${ }^{26} \mathrm{Al} /{ }^{27} \mathrm{Al}$ at the time of $\mathrm{CAI}$ formation suggest that the time interval 
' $\Delta$ ' between the last addition of freshly synthesized material into the solar nebula and the formation of some of the first solar system solids (CAIs) could be a few million to about ten million years. This follows from the fact that the value of ${ }^{26} \mathrm{Al} /{ }^{27} \mathrm{Al}$ in freshly synthesized material varies from $\sim 1$ to $10^{-3}$ depending on the stellar nucleosynthesis sites [e.g. AGB star, Wolf-Ryat star, nova or supernova (Clayton and Leising 1987)]. The above time scale is in fact an upper limit as we must also take into account the fact that the freshly synthesized ${ }^{26} \mathrm{Al}$ injected into the nebula will get diluted with pre-existing material of normal isotopic composition (see, e.g. Wasserburg 1985).

In an attempt to further constrain the value of $\Delta$, we have looked for the possible presence of ${ }^{41} \mathrm{~K}$ excess in CAIs that could result from the decay of ${ }^{41} \mathrm{Ca}$ with an even shorter half-life $\left(\sim 10^{5} \mathrm{yr}\right)$ than ${ }^{26} \mathrm{Al}$. Results obtained in earlier studies of potassium isotopic composition in CAIs from the primitive meteorite Allende were inconclusive, although the data of Hutcheon et al (1984) provided a hint of possible ${ }^{41} \mathrm{~K}$ excess in a couple of Allende CAIs. The unaltered nature of the Efremovka CAIs and the presence of high $\mathrm{Ca} / \mathrm{K}$ pyroxene (fassaite) make them ideal candidates for this study. We have analyzed two Efremovka CAIs showing ${ }^{26} \mathrm{Mg}$ excess along with appropriate terrestrial standards for their potassium isotopic composition. As in the case of magnesium isotopes, we can write the following relation for the $\mathrm{K}-\mathrm{Ca}$ isotopic systematics:

$$
\begin{aligned}
{\left[{ }^{41} \mathrm{~K} /{ }^{39} \mathrm{~K}\right]_{m} } & =\left[{ }^{41} \mathrm{~K} /{ }^{39} \mathrm{~K}\right]_{i}+\left[{ }^{41} \mathrm{~K} * /{ }^{39} \mathrm{~K}\right] \\
& =\left[{ }^{41} \mathrm{~K} /{ }^{39} \mathrm{~K}\right]_{i}+\left[{ }^{41} \mathrm{Ca} /{ }^{40} \mathrm{Ca}\right]_{i} \times\left[{ }^{40} \mathrm{Ca} /{ }^{39} \mathrm{~K}\right]_{m}
\end{aligned}
$$

The measurements of the potassium isotopic ratios were carried out at a mass resolution of $\sim 5,000$, sufficient to remove the hydride interference $\left({ }^{40} \mathrm{CaH}\right)$ on ${ }^{41} \mathrm{~K}$. However it is not possible to resolve the doubly charged interference $\left({ }^{40} \mathrm{Ca}^{42} \mathrm{Ca}\right)^{++}$ at ${ }^{41} \mathrm{~K}$, and we have corrected for this interference by monitoring the $\left({ }^{40} \mathrm{Ca}^{43} \mathrm{Ca}\right)^{++}$ signal at mass $41 \cdot 5$. Since the signal at ${ }^{41} \mathrm{~K}$ in the meteoritic phases were rather low (typically $<1 \mathrm{c} / \mathrm{s}$ ) extreme care was taken to ensure that all the instrument parameters including the background of the pulse counting system remained stable and wellbehaved during these analyses. Terrestrial pyroxenes were analyzed in between meteoritic samples. The magnitudes of the $\left({ }^{40} \mathrm{Ca}^{43} \mathrm{Ca}\right)^{++}$signal and possible tail contributions (from the left shoulder of the hydride peak) to ${ }^{41} \mathrm{~K}$ as well as the background of the pulse counting system were monitored at the masses $41 \cdot 5,{ }^{43} \mathrm{Ca}-\delta \mathrm{M}$ $\left[\delta \mathrm{M}=\left({ }^{40} \mathrm{CaH}-{ }^{41} \mathrm{~K}\right)\right]$ and 40.7 (blank) respectively. The details of the experimental procedures are reported elsewhere (Srinivasan et al 1993a, b). In table 5 we show the results obtained from analysis of pyroxenes in Efremovka CAIs E44 and E65 along with results on terrestrial pyroxenes with contrasting $\mathrm{Ca} / \mathrm{K}$ ratios. The measured ${ }^{41} \mathrm{~K} /{ }^{39} \mathrm{~K}$ ratios were corrected appropriately for the $\left({ }^{40} \mathrm{Ca}^{42} \mathrm{Ca}\right){ }^{++}$interference (see table 5). The contribution from the hydride tail was found to be below the dynamic background of the counting system and was neglected. The measured ${ }^{41} \mathrm{~K} /{ }^{39} \mathrm{~K}$ values for the terrestrial samples with extreme $\mathrm{Ca} / \mathrm{K}$ ratios $\left(10^{-3}, 2 \times 10^{4}\right.$ and $\left.3 \times 10^{6}\right)$ are consistent with the reference value of 0.072 and suggest that the doubly charged interference has been corrected appropriately in all the cases. The measured values in the meteoritic pyroxenes, particularly those with $\mathrm{Ca} / \mathrm{K}>3 \times 10^{5}$, indicate the clear presence of excess ${ }^{41} \mathrm{~K}$. The excess ${ }^{41} \mathrm{~K}$ is also well correlated with the ${ }^{40} \mathrm{Ca}$ content 
Table 5. K-Ca isotopic data.

\begin{tabular}{|c|c|c|}
\hline Sample & $\begin{array}{c}{ }^{40} \mathrm{Ca} /{ }^{39} \mathrm{~K}^{2} \\
\pm 2 \sigma_{m}\end{array}$ & $\begin{array}{l}{ }^{41} K / /^{39} K^{b} \\
\quad \pm 2 \sigma_{m}\end{array}$ \\
\hline & \multicolumn{2}{|c|}{ Terrestrial phases } \\
\hline $\begin{array}{l}\text { Microline }^{c} \\
\text { Pyroxene } 1^{d} \\
(T-P X-1)\end{array}$ & $\begin{array}{c}\sim 10^{-3} \\
\sim 2 \cdot 1 \times 10^{4}\end{array}$ & $\begin{array}{l}0.07187 \pm 0.0001 \\
0.07301 \pm 0.0012\end{array}$ \\
\hline $\begin{array}{l}\text { Pyroxene } 2^{c} \\
\text { (CAI-PX-3) }\end{array}$ & $\sim 3 \times 10^{6}$ & $0-06999 \pm 0-0064$ \\
\hline
\end{tabular}

Efremovka CAls (pyroxene)

E65

\begin{tabular}{lll}
\hline$\# 1$ & $(7.30 \pm 0.81) \times 10^{4}$ & $0.07399 \pm 0.0017$ \\
$\# 2$ & $(2.67 \pm 0.29) \times 10^{5}$ & $0.07782 \pm 0.0044$ \\
$\# 3$ & $(5.87 \pm 0.85) \times 10^{4}$ & $0.07176 \pm 0.0018$ \\
$\# 4$ & $(9.73 \pm 1.33) \times 10^{4}$ & $0.07122 \pm 0.0020$ \\
$\# 5$ & $(1.75 \pm 0.28) \times 10^{5}$ & $0.07441 \pm 0.0028$ \\
$\# 6$ & $(1.52 \pm 0.42) \times 10^{5}$ & $0.07646 \pm 0.0039$ \\
$\# 7$ & $(9.34 \pm 0.54) \times 10^{5}$ & $0.08390 \pm 0.0085$ \\
$\# 8$ & $(9.87 \pm 0.95) \times 10^{5}$ & $0.09311 \pm 0.0107$ \\
$\# 9$ & $(5.94 \pm 0.66) \times 10^{5}$ & $0.08303 \pm 0.0088$ \\
$\# 10$ & $(1.28 \pm 0.06) \times 10^{6}$ & $0.09738 \pm 0.0100$ \\
$\# 11$ & $(3.55 \pm 0.30) \times 10^{6}$ & $0.08934 \pm 0.0426$ \\
$\# 12$ & $(2.18 \pm 0.11) \times 10^{6}$ & $0.09851 \pm 0.0218$
\end{tabular}

\begin{tabular}{lll}
\hline \#1 & $(2.84 \pm 0.39) \times 10^{6}$ & $0.15437 \pm 0.0398$ \\
$\# 2$ & $(2.44 \pm 0.14) \times 10^{6}$ & $0.13015 \pm 0.0103$
\end{tabular}

-The values for meteoritic phases were obtained from ion microprobe data using an ion yield of 3.2 , favouring the $K$ isotopes over $\mathrm{Ca}$ isotopes during sputtering. The yield factor is based on analysis of terrestrial pyroxene with high $\mathrm{Ca} / \mathrm{K}$. bValues are corrected for $\left({ }^{40} \mathrm{Ca}{ }^{42} \mathrm{Ca}\right)^{++}$interference by using the measured value of $(2.64 \pm 0.09) \times 10^{-5}$ for $\left[\left({ }^{40} \mathrm{Ca}^{43} \mathrm{Ca}\right)^{++} /{ }^{43} \mathrm{Ca}{ }^{+}\right]$in tertestrial and meteoritic pyroxene and $\left({ }^{42} \mathrm{Ca}^{+} /{ }^{39} \mathrm{~K}^{+}\right)$from meteoritic pyroxene.

'US National Museum Standard (USNM 143966).

¿Sample prepared at Caltech (Courtesy I. Hutcheon).

of the analyzed phases (see figure 9) and yields a value of $(2 \cdot 1 \pm 0 \cdot 3) \times 10^{-8}$ for the initial ${ }^{41} \mathrm{Ca} /{ }^{40} \mathrm{Ca}$ at the time of formation of Efremovka CAIs.

The observed ${ }^{41} \mathrm{~K}$ excess and its correlation with ${ }^{40} \mathrm{Ca}$ in the Efremovka samples could in principle be due to secondary neutron induced reaction $\left[{ }^{40} \mathrm{Ca}(n, \gamma)^{41}\right.$ $\mathrm{Ca} \rightarrow{ }^{41} \mathrm{~K}$ ] during the cosmic ray exposure of this meteorite in interplanetary space. However, this possibility can be ruled out as the required neutron fluence is extremely high $\left(\sim 3 \times 10^{16} \mathrm{~cm}^{-2}\right)$. The neutron fluence experienced by Efremovka has not been measured directly, but a fairly good estimate can be made by considering the neutron 


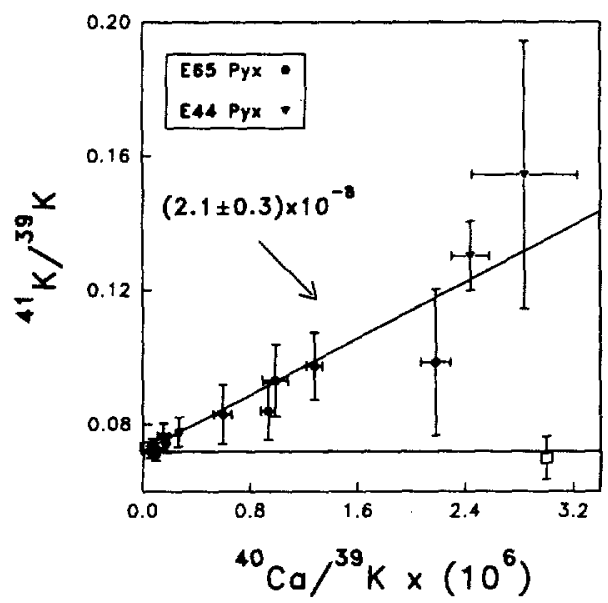

Figure 9. Plot of measured ${ }^{41} \mathrm{~K} /{ }^{39} \mathrm{~K}$ vs ${ }^{40} \mathrm{Ca} /{ }^{39} \mathrm{~K}$ in pyroxenes from Efremovka CAIs E44 and E65. The open symbols represent data for terrestrial pyroxenes, the horizontal line represents the reference potassium isotopic ratio $(0.072)$. The slope of the best fit line $(2 \cdot 1 \pm 0 \cdot 3) \times 10^{-8}$ represents initial ${ }^{41} \mathrm{Ca} /{ }^{40} \mathrm{Ca}$.

fluence $\left(<10^{15} \mathrm{~cm}^{-2}\right)$ experienced by the Allende meteorite (Göbel et al 1982). The Allende meteorite had a preatmospheric size much larger than Efremovka but a cosmic ray exposure age ( $\sim 5 \mathrm{Ma})$, about half that of Efremovka ( $\sim 10 \mathrm{Ma})$. Since the secondary neutron fluence experienced by a meteorite increases with its exposure age and size, the fluence experienced by Efremovka cannot be more than twice the Allende value. Thus the expected neutron fluence in Efremovka falls short of the required value by more than an order of magnitude to generate the excess ${ }^{41} \mathrm{~K}$ seen in Efremovka CAIs during its cosmic ray exposure. Our data provide the first reliable evidence for the presence of the short-lived nuclide ${ }^{41} \mathrm{Ca}$ in the early solar system.

To calculate the time interval ' $\Delta$ ' from the measured initial ${ }^{41} \mathrm{Ca} /{ }^{40} \mathrm{Ca}$ in the Efremovka CAIs we need to estimate the nucleosynthetic input of ${ }^{41} \mathrm{Ca}$ and the extent of nebular dilution. We estimate this input based on the following plausible assumptions: (i) the nucleosynthetic yield of the isotopes resembled solar abundances, (ii) the abundance of ${ }^{41} \mathrm{Ca}$ was close to that of the other odd mass stable calcium isotope ${ }^{43} \mathrm{Ca}$ and (iii) ${ }^{41} \mathrm{~K}$ was produced exclusively via its radioactive progenitor ${ }^{41} \mathrm{Ca}$ (Woosely et al 1973). These assumptions yield a value of $\sim 1-4 \times 10^{-3}$ for ${ }^{41} \mathrm{Ca} /{ }^{40} \mathrm{Ca}$ ratio. The measured value of $(2 \cdot 1 \pm 0 \cdot 3) \times 10^{-8}$ would then imply a time interval of $\leqslant 2 \mathrm{~m} . \mathrm{y}$. in the absence of nebular dilution. This value will be close to or less than a million years if we allow for a plausible nebular dilution factor of $\sim 10^{3}$ to $10^{4}$ (Wasserburg 1985). This estimate is not inconsistent with that from $\mathrm{Mg}-\mathbf{A l}$ data as the input value for freshly synthesized ${ }^{26} \mathrm{Al}$ is not as tightly constrained as in the case of ${ }^{41} \mathrm{Ca}$. The data on both ${ }^{26} \mathrm{Mg}$ and ${ }^{41} \mathrm{~K}$ excess in Efremovka CAIs, therefore, indicate that the time interval between the last addition of freshly synthesized material prior to the isolation of the solar nebula and the formation of some of the first solar system solids (CAIs) is close to a million years. 


\section{Summary and conclusions}

A high mass resolution secondary ion mass spectrometer (ion microprobe) has been successfully used for the measurement of isotopic compositions of magnesium, calcium, titanium and potassium in terrestrial and meteoritic samples. Extensive tests were carried out to ensure that conditions necessary for reproducible and highprecision isotopic measurements are met by the instrument. The ion microprobe can be routinely tuned for a mass resolution $(\mathrm{M} / \Delta \mathrm{M})$ of $\sim 5000$, which is needed to resolve the hydride interferences in the mass region of our interest $(A<70)$. Operation at extremely high mass-resolution $(M / \Delta M \sim 10,000)$, needed for resolving specific isobaric interferences, also give reproducible results. The dynamic stability of the instrument during high mass resolution measurements is very good, the effective magnetic field stability $(\Delta \mathrm{B} / \mathrm{B})$ being about $10 \mathrm{ppm}$. The effective dead-time of the integrated pulse counting system is $<25 \mathrm{nsec}$ and remains stable for periods of several weeks with a standard deviation of $\leqslant 2 \mathrm{nsec}$. The dynamic background of the counting system is $<0.01 \mathrm{c} / \mathrm{s}$.

Measurement of terrestrial standards as well as isotopically doped silicate glasses gave good results with a precision of $2 \%\left(2 \sigma_{m}\right)$ for magnesium isotopic analysis even on samples with low $\mathrm{Mg}$ content (few hundred $\mathrm{ppm}$ ). Reliable measurements of isotopic compositions of other elements (e.g. Ca and $\mathrm{Ti}$ ) that requires extremely high mass resolution $(\mathrm{M} / \Delta \mathrm{M} \sim 10,000)$ could also be performed with high precision.

Results of magnesium and potassium isotopic analyses in a set of $\mathrm{Ca}-\mathrm{Al}$-rich refractory inclusions (CAIs) from the primitive carbonaceous chondrites Efremovka and Grosnaja are presented. Four out of six CAIs from Efremovka and Grosnaja analyzed by us have excess ${ }^{26} \mathrm{Mg}$ indicating the presence of live ${ }^{26} \mathrm{Al}\left(t_{1 / 2}=7 \times 10^{5} \mathrm{yr}\right)$ in the solar nebula at the time of their formation. The pristine nature of the Efremovka CAIs suggested by their petrographic and trace element characteristics is corroborated by the isotopic data. The initial ${ }^{26} \mathrm{Al} /{ }^{27} \mathrm{Al}$ values for the Efremovka CAIs studied in this and earlier work are close to the value of $5 \times 10^{-5}$ found in petrographically unaltered CAIs from other primitive meteorites. The Grosnaja CAIs showing petrographic evidence for secondary alterations are also characterized by much lower initial ${ }^{26} \mathrm{Al} /{ }^{27} \mathrm{Al}$ and disturbed $\mathrm{Mg}-\mathrm{Al}$ systematics. We suggest that the variation in ${ }^{26} \mathrm{Mg}$ excess seen in a large number of CAIs, many of which show clear signs of secondary petrographic alteration, is primarily due to post-formation processes leading to reequilibration or exchange/redistribution of magnesium isotopes in these objects. We do not agree with the view that this variation implies an extremely heterogeneous distribution of ${ }^{26} \mathrm{Al}$ in the nebula and propose that the distribution of ${ }^{26} \mathrm{Al}$ in the solar nebula at least in the region of CAI formation was relatively uniform with a ${ }^{26} \mathrm{Al} /{ }^{27} \mathrm{Al}$ value of $\sim 5 \times 10^{-5}$ at the time of CAI formation.

Several of the Efremovka CAIs with excess ${ }^{26} \mathrm{Mg}$ also have excess ${ }^{41} \mathrm{~K}$ resulting from the decay of ${ }^{41} \mathrm{Ca}\left(t_{1 / 2} \sim 10^{5} \mathrm{yr}\right)$ corresponding to an initial ${ }^{41} \mathrm{Ca} /{ }^{40} \mathrm{Ca}$ ratio of $\sim 2 \times 10^{-8}$ at the time of CAI formation. This is the first reliable demonstration for the presence of ${ }^{41} \mathrm{Ca}$ in the early solar system. The presence of excess ${ }^{26} \mathrm{Mg}$ and ${ }^{41} \mathrm{~K}$ in the Efremovka CAIs helps to constrain the time interval between the last addition of freshly synthesized material prior to the isolation of the solar nebula and the formation of some of the first solar system solids (Efremovka CAIs) to about a million years. 


\section{Acknowledgements}

We are grateful to the Department of Space, Govt. of India, for providing the necessary funds for acquiring the ion microprobe. We thank Mr. V G Shah for excellent technical support in the maintenance of the ion microprobe. We thank Dr. A A Ulyanov for providing petrographic and chemical data for the meteorite samples and for many extremely fruitful discussions. We are grateful to Profs. V K Gaur, K Gopalan and Yu A Shukolyukov for their keen interest in this work. The terrestrial standards were provided by Drs. G MacPherson, E Zinner and A A Ulyanov. The isotopically doped anorthositic glasses and the high $\mathrm{Ca} / \mathrm{K}$ pyroxenes were prepared at $\mathrm{Caltech}$ and were provided by Dr. I D Hutcheon. We thank Profs. K Gopalan and G Lugmair for their helpful reviews. The meteorite samples analyzed in this study were made available through the Indo-Russian collaboration project B- 2.4 supported by the Department of Science and Technology.

\section{References}

Armstrong J T, Huneke J C, Shaw H F, Finnerty T A and Wasserburg G J 1982 Standard $\mathrm{CaAl}_{2} \mathrm{Si}_{2} \mathrm{O}_{8}$ glasses with various $\mathrm{Mg}$ isotopic compositions for ion microprobe characterization; In: Microbeam Analysis - 1982 (ed. K F J Heinrich) (San Fransisco Press) pp. 202-204

Begemann F 1980 Isotopic anomalies in metcorites; Rept. Prog. Phys. 43 1309-1356

Clayton D D and Leising M D $1987{ }^{26} \mathrm{Al}$ in the interstellar medium; Phys. Rep. 144 1-50

Clayton R N, Mayeda T K and Grossman L 1973 A component of primitive nuclear composition in carbonaceous chondrites; Science $182485-488$

Clayton R N 1978 Isotopic anomalies in early solar system; Ann. Rev. Nucl. Part. Sci. 28 501-522

Clayton R N, Hinton R W and Davis A M 1988 Isotopic variations in rock forming elements in meteorites: Philos. Trans. R. Soc. (London) A325 483-501

Curien H, Guillemin C, Orcel J and Sternberg M 1956 La hibonite, nouvelle espece minerale; Compt. Rend. 242 2845-2847

Fahey A, Goswami J N, McKeegan K D and Zinner E 1985 Evidence for extreme ${ }^{50} \mathrm{Ti}$ enrichment in primitive meteorites; Ap. J. (Lett.) 296 L17-20

Fahey A, Goswami J N, McKeegan K D and Zinner E $1987{ }^{26} \mathrm{Al},{ }^{244} \mathrm{Pu},{ }^{50} \mathrm{Ti}, \mathrm{REE}$, and trace element abundances in hibonite grains from CM and CV meteorites; Geochim. Cosmochim. Acta 51 329-350

Göbel R, Begemann F and Ott U 1982 On neutron-induced and other noble gases in Allende inclusions; Geochim. Cosmochim. Acta 46 1777-1792

Goswami J N, Shah V G and Srinivasan G 1991 Isotopic studies by a secondary ion mass spectrometer: Parametric investigations; Proc. 5th National Symp. on Mass Spec. (Ahmedabad, India) Paper EPS-18/1-4

Goswami J N, Srinivasan G and Ulyanov A A 1993a Grosnaja ABCs: Magnesium isotope composition; Lunar Planet. Sci. XXIV 553-554

Goswami J N, Srinivasan G and Ulyanov A A 1993b Ion microprobe studies of Efremovka CAIs-II: Isotopic systematics in a multi-zoned hibonite-rich inclusion; (In preparation)

Goswami J N, Srinjvasan G and Ulyanov A A 1994 Ion microprobe studies of Efremovka CAIs-I: Magnesium isotope composition; Geochim Cosmochim Acta 58 431-447

Grossman L 1972 Condensation in the primitive solar nebula: Geochim. Cosmochim. Acta 36 597-619

Grossman L 1980 Refractory inclusions in the Allende meteorite; Ann. Rev. Earth Planet. Sci. $8559-608$

Harper C L 1993 Isotopic astronomy from anomalies in meteorites: Recent advances and new frontiers; J. Phys. G. (Nucl. Part. Phys.) $19581-594$

Huneke J C, Armstrong J T and Wasserburg G J 1983 FUN with PANURGE: High mass resolution ion microprobe measurements of $\mathrm{Mg}$ in Allende inclusions; Geochim. Cosmochim. Acta 47 1635-1650

Hutcheon I D 1982 Ion probe magnesium isotopic measurements of Allende inclusions; Am. Chem. Soc. Symp. Series 176 95-128 
Hutcheon I D, Armstrong J T and Wasserburg G J 1984 Excess ${ }^{4} \mathrm{~K}$ in Allende CAI: A hint reexamined: Meteoritics 19 243-244

Ireland T R, Compston W and Heydegger H R 1985 Titanium isotopic anomalies in hibonites from Murchison carbonaceous chondrite; Geochim. Cosmochim. Acta 49 1989-1993

Ireland T R 1990 Presolar isotopic and chemical signatures in hibonite-bearing refractory inclusions from the Murchison carbonaceous chondrite; Geochim. Cosmochim. Acta 54 3219-3237

Jungek M H A, Shimamura T and Lugmair G W $1984 \mathrm{Ca}$ isotope variations in Allende; Geochim. Cosmochim. Acta 48 2651-2658

Lepareur M 1980 Le micro-analyseur ionique de seconde generation Cameca, Model 3F; Rev. Tech. Thomson-CSF 12 225-265

Lee T, Papanastassiou D A and Wasserburg G J 1976 Demonstration of ${ }^{26} \mathrm{Mg}$ excess in Allende and evidence for ${ }^{26}$ Al; Geophys. Res. Lett. 3 109-112

Lee T 1979 New isotopic clues to solar system formation; Rev. Geophys. Space Phys. 17 1591-1611

Lee T 1988 Implications of isotopic anomalies for nucleosynthesis; In: Meteorites and Early Solar System (eds) J F Kerridge and M S Matthews (Tucson: Arizona Univ. Press) pp. 1063-1089

Macdougall J D and Goswami J N 1981 Windows to early solar system processes: Refractory inclusions in CV and CM chondrites; Proc. Indian Acad. Sci. (Earth Planet. Sci.) 50 1-26

MacPherson G J, Wark D A and Armstrong J T 1988 Primitive material surviving in chondrites: Refractory inclusions; In: Meteorites and Early Solar System (ed.) J F Kerridge and M S Matthews, (Tucson: Arizona Univ. Press) pp. 746-807

MacPherson G J, Davis A M and Zinner E K 1992 Distribution of ${ }^{26} \mathrm{Al}$ in the early solar system - a reappraisal; Meteoritics 27 253-254

McKeegan K D. Walker R M and Zinner E 1985 Ion microprobe isotopic measurement of individual interplanetary dust particle; Geochim. Cosmochim. Acta 49 1971-1987

Nazarov M A, Ulyanov A A, Korina M I and Kolesov G M 1982 Efremovka CAI's: Major and trace element chemistry; Lunar Planet. Sci. XIII 584-585

Niederer F R and Papanastassiou D A 1984 Ca isotopes in refractory inclusions; Geochim. Cosmochim. Acta 48 1279-1294

Podosek F A 1978 Isotopic structures in solar system materials; Ann. Rev. Astron. Astrophys. 16 293-334

Podosek F A, Zinner E K, MacPherson J G, Lundberg L L, Brannon C J and Fahey A J 1991 Correlated study of initial ${ }^{87} \mathrm{Sr} /{ }^{87} \mathrm{Sr}$ and $\mathrm{Al}-\mathrm{Mg}$ isotopic systematics and petrologic properties in a suite of refractory inclusions from the Allende meteorite; Geochim. Cosmochim. Acta 55 1083-1110

Slodzian G, Chaintreau M P and Dennebouy R C 1987 Self regulated potential at insulating surfaces in presence of a strong electrostatic extraction fieid; Proc. 11th Int. Conf. on $X$-ray optics and microanalysis (Canada)

Srinivasan G, Ulyanov A A and Goswami J N 1993a Search for ${ }^{41} \mathrm{~K}$ excess in Efremovka CAIs; Meteoritics 28442

Srinivasan G, Ulyanov A A and Goswami J N $1993 b^{41} \mathrm{Ca}$ in the early solar system (In preparation)

Thiemens M H 1988 Heterogeneity in the nebula: evidence from stable isotopes; In: Meteorites and Early Solar System (eds) J F Kerridge and M S Matthews, (Tucson: Arizona Univ. Press) pp. 899-923

Ulyanov A A, Korina M I, Nazarov M A and Sherbovsky E Ya 1982 Efremovka carbonaceous chondrite; Lunar Planet. Sci. XIII 813-814

Virag A, Zinner E, Amari S and Anders E 1991 An ion microprobe study of corundum in the Murchison meteorite: Implications for ${ }^{26} \mathrm{Al}$ and ${ }^{16} \mathrm{O}$ in the early solar system; Geochim. Cosmochim. Acta 54 2045-2062

Wasserburg G J, Papanastassiou D A and Lee T 1980 Isotopic heterogeneities in solar system; In: Early Solar System and Present Solar System (ed.) D Lal (North Holland, Amsterdam) pp. 144-191

Wasserburg G J and Papanastassiou D A 1982 Some short-lived nuclides in the early solar system - A connection with the placental ISM; In: Essays in Nuclear Astrophysics (eds) C A Barnes, D D Clayton and D N Schramm (Cambridge Univ. Press) pp. 77-140

Wasserburg G J 1985 Short-lived nuclei in early solar system; In: Proto Stars and Planets II (ed.) D C Black and M S Matthews (Tucson: Arizona Univ. Press) pp. 703-737

Woosley S E, Arnett W D and Clayton D D 1973 The explosive burning of oxygen and silicon; Ap. J. (Suppl.) 231 231-312 